\title{
Investigation on the performance of a heat recovery ventilator in different climate regions in China
}

\author{
Lingling $\mathrm{Bao}^{\mathrm{a}, \mathrm{b}^{*}}$, Jinggang Wang ${ }^{\mathrm{a}^{*}}$ and Hongxing Yang ${ }^{\mathrm{b}}$ \\ ${ }^{a}$ School of Urban Construction, Hebei University of Engineering, Handan, China. \\ ${ }^{b}$ Department of Building Services Engineering, The Hong Kong Polytechnic University, Hong Kong, China. \\ Correspondingemail: lingling5934@163.com \& jinggangwang@hebeu.edu.cn. \\ Tel.: +863108579100.
}

\begin{abstract}
In recent years, haze becomes a choking problem in northern China in winter. A heat recovery ventilator (HRV) is an effective device to provide clean indoor environment by supplying fresh outdoor air to residential and commercial buildings, but the HRV system must be combined with an air filter to remove the fine particular matter of the outdoor air. There is limited information regarding this integrated system. This paper investigates the influences of an air filter on the performances of the HRV system in three modes by experiment and the application potential is also reported for this integrated system in five climate zones of China. The experimental results show that the integrated system can meet the required threshold value of $75 \mu \mathrm{g} / \mathrm{m}^{3}$, but the installation of an air filter reduces the air flow rate and increases the power of the fan. Compared to the HRV system, the sensible heat efficiencies of the integrated system are increased; and the total sensible heat transfer capacities are slightly decreased in the three modes. The case study shows that in Harbin and Beijing, the integrated system can recover more energy than that in other three cities in winter.
\end{abstract}

Keywords: heat recovery ventilator (HRV); air filter; experiment; performance; comparison

\begin{tabular}{|ll|}
\hline Nomenclature & \\
HRV & heat recovery ventilator \\
ERV & energy recovery ventilator \\
$\eta_{s}$ & sensible heat efficiency \\
$Q_{s}$ & sensible heat transfer capacity, $\mathrm{kW}$ \\
$Q_{h}$ & fresh air sensible heating load, $\mathrm{kW}$ \\
$G$ & air flow rate, $\mathrm{kg} / \mathrm{s}$ \\
$c_{p}$ & specific heat capacity at constant pressure, $\mathrm{kJ} /\left(\mathrm{kg}{ }^{\circ} \mathrm{C}\right)$ \\
$t$ & temperature, ${ }^{\circ} \mathrm{C}$ \\
$\varphi$ & relative humidity, $\%$ \\
$\dot{Q_{h}}$ & accumulative fresh air sensible heating load, $\mathrm{kWh}$ \\
$\dot{Q_{s}}$ & accumulative sensible heat recovery capacity, $\mathrm{kWh}$ \\
$H$ & running hours of the $\mathrm{HRV} /$ integrated system, $\mathrm{hr}$ \\
$C$ & concentration of $\mathrm{PM} 2.5, \mu \mathrm{g} / \mathrm{m}^{3}$ \\
\hline
\end{tabular}




\begin{tabular}{|ll|}
\hline$P$ & static pressure, $\mathrm{Pa}$ \\
$v$ & air velocity, $\mathrm{m} / \mathrm{s}$ \\
Subscripts & \\
$s$ & sensible \\
in & indoor \\
out & outdoor \\
1 & inlet \\
2 & outlet \\
$\tau$ & the $\tau^{\text {th }}$ hour \\
\hline
\end{tabular}

\section{Introduction}

Buildings are equipped with heating, ventilating, and air-conditioning (HVAC) systems which are better insulated and tighter for less infiltration to decrease the energy consumption in winter in northern China. In order to meet the requirement of indoor air quality (IAQ), large quantity of fresh air has to be brought into the rooms which results in more energy consumption for heating and cooling fresh air. Applications of the energy recovery ventilator (ERV) and heat recovery ventilator (HRV) are effective solutions for this issue ${ }^{[1]}$. The ERV and HRV are widely used in some Europe countries ${ }^{[2,3]}$, but not in China. The public building code in China issued in 2005 states that the HRV or ERV should be installed in HVAC systems ${ }^{[4]}$. The exhaust air passes through one side of the ventilator with counter flow passing through the other side of ventilator to bring fresh air from outdoor. In a HRV, sensible heat will be exchanged between the exhaust air and the fresh air through the heat transfer channels. In an ERV, both sensible and latent heat will be exchanged between them. Although the heat recovery efficiency of the ERV is higher than that of the HRV, the maintenance fee and the initial cost of the ERV are higher than that of the HRV [2, ${ }^{5]}$. Moreover, in an ERV the contaminants would be transferred from exhaust to supply air ${ }^{[6-8]}$. The problem of balancing energy conservation and cost is more complicated owning to different climates, indoor design conditions and heat exchange efficiency of the HRV or ERV, etc. ${ }^{[9]}$ Zhang and Liu ${ }^{[10,11]}$ propose that the ERV is suitable and recommended for hot and humid regions, while the HRV is more efficient in cold regions.

In recent years, air pollution becomes a choking problem in China, and the fine particular matter (PM2.5) in air is the critical pollutant ${ }^{[12]}$ which plays an important role in human health problem ${ }^{[13,14]}$ in northern China now. Wang ${ }^{[15]}$ reported that in dry and cold winter in Beijing, the PM2.5 concentration of the outdoor air is higher than that in summer. In January 2013, the PM2.5 concentration of the outdoor air was increased to $500-800 \mu \mathrm{g} / \mathrm{m}^{3}$ in Beijing ${ }^{[16]}$ which greatly exceeds the current Chinese Ambient Quality Standards of $75 \mu \mathrm{g} / \mathrm{m}^{3}$ for $24-\mathrm{h}$ average ${ }^{[17]}$. Because of the poor outdoor air quality, the HRV alone is invalid for improving the IAQ of the indoor space by supplying the outdoor air to the room directly. A high efficiency particular air (HEPA) filter is necessary to be installed upstream of the HRV to clean the outdoor air. This paper is to investigate the effect of the air filter on the performance of the HRV.

Some studies have focused on the performances of the HEPA filter on PM2.5 mass concentrations. Spilak et al. ${ }^{[18]}$ state that the particle filtration units can help reduce the PM2.5 concentrations by $54.5 \%$ in dwellings. Zaatari et al. ${ }^{[19]}$ investigate the relationship among the 
filter pressure drop, the indoor air quality and energy consumption in the rooftop HVAC units. The result shows that choosing the right efficiency of filters is essential to ensure low-energy adoption and a healthy indoor environment. Marsik et al. ${ }^{20]}$ present a dynamic model for evaluating the indoor PM2.5 levels and energy consumption associated with ventilation. The result demonstrates that using a HRV with an additional filter can save about US\$690 annually compared with using natural ventilation.

The integrated system of a HRV plus an air filter can solve two issues, i.e. energy saving and better IAQ in cold climate regions. On the one hand, a HRV of the integrated system could recover energy from the indoor exhaust air, and the filters could clean the polluted outdoor air, so that cleaner outdoor air can be supplied to the room space for improving the indoor air quality. The energy conservation capacity is dependent on the efficiency of the HRV and the parameters of both indoor and outdoor air ${ }^{[2]}$. On the other hand, compared with a HRV alone, the filters would increase the flow resistance and lower the flow rate of the integrated system which would result in higher energy consumption. The influence of an air filter on the performances of the HRV must be investigated.

In this paper, the resistance characteristics and sensible heat efficiency of both the HRV alone and the integrated system are investigated by experiment; the influence of the air filter on the performances of HRV is analyzed. Meanwhile, the sensible heat efficiency and the sensible heat transfer capacity of the two systems are compared. A typical residential apartment is an example, whose energy consumption and heat recovery of the integrated system are analyzed whether it is adoptable in different climate zones of China in winter.

\section{Methodology}

\subsection{Experimental setup}

In order to remove PM2.5 economically, a counter-cross flow sensible plate heat exchanger and an F7 air filter according to EU standard ${ }^{[21]}$ are chosen for investigation in this project. The experimental system and test points are presented in Fig.1. The specifications of each main component are listed in Table 1. The HRV has 3 possible air flux settings: "Min," "Norm" and "Max." The heat exchange element is VM1 type produced by Systemair AB in Sweden, and it is made of an alloy steel plate with the thickness of $0.3 \mathrm{~mm}$. The channel width of heat exchange element is about $40 \mathrm{~mm}$. The outdoor air can be cooled by an air cooler installed in the duct to simulate cold air outside. In order to simulate high concentrations of PM2.5 outdoor air, a solid particle disperser is necessary.

(a) Schematic diagram of the experimental facility.

(b) Photos of the experimental setups.

Fig. 1. Experimental setup.

Table 1 Specifications of the Main Components of the Test Rig. 


\subsection{Instrumentation}

Table 2 Specifications of the instruments.

The specifications of the instruments are listed above in Table 2. The dry bulb temperature and relative humidity at the inlets and outlets of the HRV were measured by the Onset HOBO data loggers (Model: U12-11, with accuracy $\pm 0.35{ }^{\circ} \mathrm{C}, \pm 2.5 \%$ ). The data were recorded automatically at every 30 seconds interval for heat transfer performance analysis. The air velocity of the inlet and outlet ducts connected to the HRV was measured by TSI VELOCICALC Plus Multi-Parameter Ventilation Meters (Model: 8386A, with accuracy $\pm 0.015 \mathrm{~m} / \mathrm{s}$ ) for calculating the air flow rate. Two TSI DP-CALC air flow micro manometers (Model: 5825, with accuracy \pm $1 \mathrm{~Pa}$ ) were located at inlet and outlet of the air filter to measure the pressure drop of the air filter. Two TSI DUSTTRAK Aerosol Particulate Monitors (Model: 5820, with accuracy $\pm 0.001 \mathrm{mg} / \mathrm{m}^{3}$ ) were installed at inlet and outlet of the air filter to measure its filtration performance. The power consumption of the HRV was measured instantaneously by an electric power measuring meter (Model: TM9, accuracy about $\pm 0.1 \mathrm{~W}$ ).

\subsection{Experimental procedures}

As shown in Fig.2, the experimental investigation consists of two tests, i.e., HRV alone and HRV combined with an air filter (integrated system). Each test has three modes, i.e., min mode, norm mode and max mode. First, to investigate the air flux, power and sensible heat transfer performances of the HRV alone in three modes were investigated. Second, to investigate the air flux, power, filtration performance and sensible heat transfer performances of HRV alone in three modes were included. It should be noted that about four steady heat transfer processes which may take 160 minutes are necessary to be adopted in investigating the heat transfer performance to obtain a fitting curves for the sensible heat efficiency.

Fig. 2. The test processes.

\subsection{Theoretical analysis of the system}

In order to investigate the effects of the air filter on the heat transfer performances of the HRV, comparative experiments have been conducted. The sensible heat efficiency is an important parameter for estimating heat transfer performance of the system. According to its definition as shown in ASHRAE standard $84^{[22]}$, we can find the equation for the sensible heat exchanger:

$\eta_{s}=Q_{s} /\left[\left(G c_{p}\right)_{\min }\left(t_{\text {in1 }}-t_{\text {out } 1}\right)\right]$

In the equation above, $\eta_{s}$ stands for sensible heat efficiency, $Q_{s}$ for total exchanged sensible heat in $\mathrm{kW}, G_{\min }$ for the air flow rate of the lower flow side in $\mathrm{kg} / \mathrm{s}, c_{p}$ for the specific heat capacity at constant pressure in $\mathrm{kJ} /\left(\mathrm{kg}{ }^{\circ} \mathrm{C}\right)$, and $t_{i n 1}$ and $t_{\text {out } 1}$ for the inlet air temperatures of the indoor and outdoor air in ${ }^{\circ} \mathrm{C}$.

For $\left(G c_{p}\right)_{\min }$ of the HRV, referring to the heat flow rate of fresh air side $G_{\text {out }} c_{p}$, we can transform Eq. (1) to Eq. (2):

$\eta_{s}=\left(t_{\text {out } 2}-t_{\text {out } 1}\right) /\left(t_{\text {in } 1}-t_{\text {out } 1)}\right)=1-\left(t_{\text {in } 1}-t_{\text {out } 2}\right) /\left(t_{\text {in } 1}-t_{\text {out } 1}\right)$ 
where $t_{\text {out } 1}$ and $t_{\text {out } 2}$ stand for inlet and outlet temperatures of outdoor air in ${ }^{\circ} \mathrm{C}$.

Zhang et al. ${ }^{[11]}$ suggest that the relationship between the sensible heat efficiency and outdoor air temperature is roughly linear if the indoor air temperature is nearly constant. While in this project, $t_{\text {in } 1}$ varies but $t_{\text {out } 1}$ is nearly constant, and $t_{\text {out } 2}$ depends on $t_{\text {in } 1}$ and $t_{\text {out } 1}$, so that $\eta_{s}$ has a nonlinear relationship with $t_{\text {in1 }}$ and $t_{\text {out } 1}$.

Suppose both $t_{i n 1}$ and $t_{\text {out } 2}$ have linear relationships with $\left(t_{\text {in } 1}-t_{\text {out } 1}\right)$, Eq. (2) can be transformed into Eq. (3):

$\eta_{s}=A-B /\left(t_{\text {in } 1}-t_{\text {out } 1}\right)$

where $A$ and $B$ refer to the coefficients obtained by the data fitting.

In order to calculate the sensible heat transfer capacity, we can transform Eq. (1) to the following one:

$Q_{s}=G_{\text {out }} c_{p}\left(t_{\text {in } 1}-t_{\text {out } 1}\right) \eta_{s}$

The equation above indicates a clear relationship among $G_{\text {out }} c_{p}, t_{\text {in } 1}$ and $t_{\text {out } 1}$.

In fact, the outdoor air temperature changes over time, so the hourly fresh air sensible heating load in winter can be obtained by Eq. (5):

$Q_{h, \tau}=W c_{p}\left(t_{\text {in }}-t_{\text {out }, \tau}\right)$

where $Q_{h, \tau}$ stands for the fresh air sensible heating load in $\mathrm{kW}, W$ for the fresh air mass flow rate in $\mathrm{kg} / \mathrm{s}$, and $t_{\text {in }}$ and $t_{\text {out }, \tau}$ for the indoor air temperature and the fresh air mean temperature at the $\tau^{\text {th }}$ hour in ${ }^{\circ} \mathrm{C}$.

Suppose if people stay indoors for $\mathrm{H}$ hours, then the accumulative fresh air sensible heating load can be calculated by,

$\dot{Q_{h}}=\sum_{\tau=0}^{H} Q_{h, \tau}$

If $G_{\text {out }}$ of HRV equals to $W$, then Eq. (7) can be obtained from Eq. (4) and Eq. (5):

$Q_{s}=Q_{h, \tau} \eta_{s}$

Similarly, the accumulative sensible heat recovery capacity $\dot{Q}_{s}$ of the integrated system can be calculated by,

$\dot{Q}_{s}=\sum_{\tau=0}^{H} Q_{h, \tau} \eta_{s}$

where $\mathrm{H}$ also stands for the running hours of the HRV/integrated system.

\section{Experimental results and discussions}

\subsection{Basic performance parameters of the two systems}

According to the fluid dynamic theory, the increase of the flow resistance of a ventilation system would result in the power consumption increase of the fan and the decrease of the air flow rate. Therefore, the basic performance parameters, i.e. the air flux, electric consumption power and the flow resistance of the air filter before and after its installation are shown in Table 3. The fresh air fluxes of the integrated system alone in the three modes are about $81.8 \mathrm{~m}^{3} / \mathrm{h}, 146.3 \mathrm{~m}^{3} / \mathrm{h}$ and $247.8 \mathrm{~m}^{3} / \mathrm{h}$ respectively, less than that of the HRV system. The total power consumption of the integrated system in the three modes are correspondingly around $17.7 \mathrm{~W}, 30.5 \mathrm{~W}$ and $112.3 \mathrm{~W}$, higher than that of the HRV system. Besides, the pressure drops of the air filter in the three modes are $10 \mathrm{~Pa}, 22 \mathrm{~Pa}$ and $65 \mathrm{~Pa}$ respectively. On the other hand, the fresh air flux of Max modes is about 3 times more than Min mode, and the power and the $\Delta \mathrm{P}$ of Max modes are about 6.5 times more than that of the Min mode. 
Table 3 Basic performance parameters.

\subsection{Filtration effects of the integrated system}

Fig. 3 shows the filtration effects of the air filter in min, norm and max modes. With the rising PM2.5 concentrations $\left(\mathrm{C}_{1}\right.$ as shown in Fig.1) at the upstream of air filter, the downstream concentration of PM2.5 ( $\mathrm{C}_{2}$ as shown in Fig.1) increases as well. As shown in the figure, when $\mathrm{C}_{1}$ are below $650 \mu \mathrm{g} / \mathrm{m}^{3}$ in min mode, $460 \mu \mathrm{g} / \mathrm{m}^{3}$ in norm mode and $430 \mu \mathrm{g} / \mathrm{m}^{3}$ in max mode, $\mathrm{C}_{2}$ is below $50 \mu \mathrm{g} / \mathrm{m}^{3}$ of the interim target-2 limit level for 24-hour average specified in WHO standard [24]. The percentage uncertainties of $C_{1}$ and $C_{2}$ are all within $\pm 6 \%$. When the inlet concentration of PM2.5 continues to increase as shown in Fig. 3, the outlet concentration of PM2.5 would exceed $50 \mu \mathrm{g} / \mathrm{m}^{3}$ and below $75 \mu \mathrm{g} / \mathrm{m}^{3}$ the limit level specified in China's standard as shown in Table $4{ }^{[17]}$. The WHO and China standards are shown in Table 4 for the annual and 24-hour average PM2.5 concentration and the three interim targets of WHO ${ }^{[17,24]}$.

Table 4 WHO and China's standards for annual and 24-hour average PM2.5 concentrations.

Fig. 3. Filtration effects of the air filter in the Min, Norm and Max modes.

\subsection{Comparison of heat transfer effects between the two systems}

According to Eq. (2) Eq. (4), both sensible heat efficiency and transfer capacity are related to the temperature differences $\left(t_{i n 1}-t_{\text {out } 1}\right)$ when the air flow rate and the structure parameters are constant. Thus, in order to compare the heat transfer effects between the two systems, the fitting curves between sensible heat efficiency and temperature differences in the three modes of the HRV should be obtained.

There are about four steady heat transfer stages for each mode test. In each steady heat transfer stage, $t_{i n 1}$ varies but $t_{\text {out } 1}$ is nearly constant. The changing curves of the four temperatures with time in the HRV system in Min mode are shown in Fig. 4. From the data shown in Fig.4, $t_{\text {out } 1}$ is nearly constant and below $t_{i n 1}$. The temperature differences vary by changing $t_{i n 1}$. It is found from Fig. 5 that both $t_{i n 1}$ and $t_{\text {out } 2}$ have nearly linear relationships with $\left(t_{\text {in } 1}-t_{\text {out } 1}\right)$. The humidity ratios of inlet and outlet air are nearly constant and around $11.47 \mathrm{~g} / \mathrm{kg}$ and $8.26 \mathrm{~g} / \mathrm{kg}$ respectively. Other tests also consist of four steady heat transfer stages as in Min mode as shown in Appendix.

Based on Eq. (2), the changing curves of the sensible heat efficiencies (the uncertainties within $\pm 3.8 \%$ ) and temperature differences (the uncertainties within $\pm 1.9 \%$ ) with time for each mode can be obtained. Fig. 6 gives the variation of the sensible heat efficiencies and temperature differences of the HRV system of the Min mode. The changing curves for other tests can also be obtained like in Fig.6.

Fig. 4. Changing curves of the four temperatures with time of the HRV system (Min mode).

Fig.5 Relation curves of $t_{i n 1} \sim\left(t_{i n 1}-t_{\text {out } 1}\right)$ and $t_{\text {out } 2} \sim\left(t_{i n 1}-t_{\text {out } 1}\right)$ of the HRV system (Min mode). 
Fig. 6. Changing curves of the sensible heat efficiency and temperature difference with time of the HRV system (Min mode).

Fig.7, Fig. 8 and Fig.9 present the comparisons of fitting curves for the sensible heat efficiencies and temperature differences between the HRV and integrated system in Min, Norm and Max modes respectively. Due to the nonlinear relationships between the sensible heat efficiencies and the temperature differences, based on the data and theoretical analyses, both the user-defined regression and the second-order polynomial models are applied to fit the curves of the sensible heat efficiency. Based on the two regression modes, the specific values of sensible heat efficiency varies with the temperature difference from $2{ }^{\circ} \mathrm{C}$ to $30{ }^{\circ} \mathrm{C}$ are calculated and shown in Table 5.

The ANOVAs (F-test) indicate that the temperature difference has significant effect on the sensible heat efficiency $(\mathrm{P}<0.001)$. The regression results are shown in Fig.7 to Fig. 9. In general, the value $\mathrm{R}^{2}$ quantifies the goodness of fit, but a higher $\mathrm{R}^{2}$ doesn't mean the fit is "good" in other ways ${ }^{[23,25]}$. In this project, the $\mathrm{R}^{2}$ is related to many factors such as the number of data points, the values of the parameters and especially the air flow rate and the structure parameters which will affect the percentage of the total variance in sensible heat efficiency that is explained by the temperature difference.

By analyzing the regression and prediction results, it is found that in the Min mode of the HRV system, the polynomial model matches much better than the user-defined model with the experimental data. Moreover, the polynomial method has a maximum sensible heat efficiency when the temperature difference is nearly $10{ }^{\circ} \mathrm{C}$ as shown in Table 5 , which is in good agreement with the test result. In the integrated system, although the regression results of the two methods are similar, the trends of the sensible heat efficiency are different. As shown in Table 5, when the temperature difference is higher than $30{ }^{\circ} \mathrm{C}$, the predicted value of the sensible heat efficiency calculated by the polynomial formula is close to even greater than 1 which is virtually impossible. Therefore, the user-defined form is better.

In the Norm mode, although the regression results show that the polynomial model is slightly better than the user-defined model, the latter can better explain the trends of sensible heat efficiency. As shown in Table 5, in the integrated system of Norm mode, when the temperature difference is higher than $26{ }^{\circ} \mathrm{C}$, the predicted value of the sensible heat efficiency calculated by the polynomial formula is greater than 1 .

In the Max mode, the regression results of the two models are similar, but the user-defined model is preferable on account of its more reasonable prediction on the trends of sensible heat efficiency. As shown in Table 5, in the HRV system of Max mode, when the temperature difference is higher than $22{ }^{\circ} \mathrm{C}$, the predicted value of the sensible heat efficiency calculated by the polynomial formula is greater than 1 . Moreover, in the integrated system, the decreased trend of the polynomial form is faster than that of the user-defined form. As shown in Table 5, when the temperature difference equals to $30^{\circ} \mathrm{C}$, the sensible heat efficiency decreased to 0.1632 . Actually, this possibility is small.

Fig. 7. Correlations for the sensible heat efficiency and temperature difference of the HRV and integrated systems (Min mode).

Fig. 8. Correlations for the sensible heat efficiency and temperature difference of the HRV and 
integrated systems (Norm mode).

Fig. 9. Correlations for the sensible heat efficiency and temperature difference of the HRV and integrated systems (Max mode).

Table 5 The sensible heat efficiencies based on the two regression methods.

\subsection{Theoretical comparisons between the HRV and integrated system}

(1) Sensible heat efficiency for different temperatures

In order to clearly compare the influence of the air filter on the sensible heat transfer efficiency of the HRV system in the three modes, Fig.10 shows the predicted results when the temperature differences vary from $2{ }^{\circ} \mathrm{C}$ to $22^{\circ} \mathrm{C}$ based on the selection regression formulas as shown in Fig. 10 . In the Min mode, no matter which fitting curve for the HRV system is chosen, $\mathrm{y} 1$ or $\mathrm{y} 1^{\prime}$, the sensible heat efficiency of the integrated system is higher than that of the HRV system when the temperature difference increases from $2{ }^{\circ} \mathrm{C}$ to $22{ }^{\circ} \mathrm{C}$. Similarly, in the Norm and Max modes, the sensible heat efficiency of the integrated system is higher than that of the HRV system. On the whole, when the temperature differences vary in a certain range, an air filter installed in the HRV system can increase the sensible heat efficiency for the three modes because the air flow rate decreases. The results in Fig. 10 show that when the temperature differences vary from $6^{\circ} \mathrm{C}$ to $22^{\circ} \mathrm{C}$, the integrated system in Norm mode has the highest sensible heat efficiency which is near 0.9 than the others, and the HRV system in Max mode has the lowest one. This denotes that the influence of an air filter on the sensible heat efficiency is complex, which is due to the combination of the temperature difference, the air flow rate, and the structure parameters, etc.

Fig. 10. Changing curves of sensible heat efficiency with temperature difference between HRV and integrated systems in the three modes.

(2) Sensible heat transfer capacity for temperature differences

Table 3 demonstrates that installing an air filter will decrease the air flow rate; conversely, Fig. 9 and Fig. 10 indicate that the sensible heat transfer efficiency will be increased. Thus, we can use the sensible heat transfer capacity presented in Eq. (4) to comprehensively evaluate the influences of an air filter on both sensible heat efficiency and air flow rate. Fig.11 shows the air filter influences on the changing curves of sensible heat transfer capacity with temperature difference varying from $0{ }^{\circ} \mathrm{C}$ to $22{ }^{\circ} \mathrm{C}$ in three modes.

As shown in Fig.11, in the three modes, although the sensible heat efficiency increases when installing an air filter, the fresh air flux decreases, thus the sensible heat transfer capacity has little difference between the HRV and integrated system according to Eq. (4) which illustrates the two effects on the sensible heat transfer capacity cancelling each other out. Therefore, as the temperature difference increases the sensible heat transfer capacity increases for the two systems. In the integrated system, when the temperature differences increase from $0{ }^{\circ} \mathrm{C}$ to $22^{\circ} \mathrm{C}$, the sensible heat transfer capacities increase from 0 to $521 \mathrm{~W}, 964 \mathrm{~W}$ and $1507 \mathrm{~W}$, respectively.

By the comprehensive analysis of the experimental results, we can see that when an air filter installed, the sensible heat transfer capacities in the three modes are slightly decreased. Thus it can be concluded that installing an air filter has a slightly bad influence on the sensible heat transfer 
capacity which is mainly determined by the air flow rate and temperature difference. However, it will increase the power of the system which leads higher energy consumption by improving the indoor air quality.

Fig.11. Changing curves of sensible heat transfer capacity with temperature difference between HRV and integrated systems in the three modes. (Notes: yi $\left(i=1,1^{\prime}, 2, \ldots \ldots, 6\right)$ indicates the sensible heat efficiency fitting formula as shown in Fig. 10 which is used to calculate the sensible heat transfer capacity).

\section{Case study}

Based on the thermal performance and resistance characteristics of the integrated system, choosing a typical residential, an apartment in the northern heating area of China, as an example, the energy saving efficiency of the integrated system applied in different climate zones in winter is analyzed below.

The detailed information of the building is given in Table 6. It is assumed that there is no infiltration air from doors and window gaps, and the temperature of the room is constant. Since the China national standard GB50376-2012, "Design code for heating ventilation and air conditioning of civil buildings ${ }^{[26]}$," prescribes the minimum volume of the fresh air system for the residential buildings according to the air change rate. As the per capita living space of this building is $25 \mathrm{~m}^{2}$, the minimum air change rate is 0.5 . Thus, the minimum volume of fresh air in the sample building is $145 \mathrm{~m}^{3} / \mathrm{h}$. It is obvious in Table 4 that the integrated system in the Norm mode can meet the requirement for fresh air.

Table 6 Descriptions of the sample building.

Since the outdoor temperature greatly affects the heat recovery capacity of the integrated system, five typical cities in different climate zones are chosen to calculate the application effects of the system in winter, i.e. Harbin in the severe cold zone, Beijing in the cold zone, Shanghai in the hot summer and cold winter zone, Kunming in the warmer zone and Guangzhou in the hot summer and warmer winter zone. The operation schedules of the integrated system are shown in Table 7. In Harbin the integrated system runs for 7 months, in Guangzhou it runs for 4 months, and in the other three cities it runs for 5 months. If people stay indoors for 12 hours per day, it also denotes the integrated system running time.

Table 7 Operation schedules of the integrated system.

Based on the above hypothesis, the accumulative fresh air sensible heating load of the apartment in different cities can be obtained according to Eq. (6), and the accumulative heat recovery capacities of the integrated system can be obtained according to Eq. (8) and the fitting equation for the integrated system as shown in Fig. 10. The calculation results of the five cities are presented in Fig. 12. It can be observed that the accumulative sensible heating load of fresh air and the heat recovery capacity are different from city to city and the descending order is Harbin, 
Beijing, Shanghai, Kunming and Guangzhou. The accumulative heat recovery capacity of the integrated is high, which accounts for more than $80 \%$ of the accumulative sensible heating load of fresh air.

Fig. 12. The sensible heating loads of the accumulative fresh air and heat recovery capacities in the five cities.

Fig.12 shows that the heat recovery capacity of integrated system is considerable. If an air-conditioner (AC) is installed in the apartment instead of the integrated system to supply the same amount of heat, the energy consumption of AC is shown in Fig.13 on the assumption that the heating COP of air-conditioner (AC) equals 2. It is observed that the energy consumption of the $\mathrm{AC}$ is much higher than that of the integrated system because of the lower power consumption fan. As for the differences between the energy consumptions of AC and integrated system in five cities, it is obvious that Harbin has the maximum benefit, and Guangzhou the minimum, which means that the integrated system can save much more energy installed in Harbin than that in Guangzhou.

Fig. 13. The energy consumptions of AC and integrated system in the five cities.

\section{Conclusions}

The influences of an air filter on the performances of a HRV system in the three running modes are shown through experimental study, and the application potential of the integrated system in the five climate zones of China is investigated. Overall, an additional filter installed in the HRV system improves IAQ but results in higher energy consumption. To be exactly, the installation of the air filter (EU F7) is sufficient to decrease PM2.5 concentration and meet the required threshold value of $75 \mu \mathrm{g} / \mathrm{m}^{3}$ specified in the national standard even the PM2.5 concentration of outdoor air is $820 \mu \mathrm{g} / \mathrm{m}^{3}$ in Min mode. However, the test results indicate that the air flux is reduced by $9.7 \sim$ $19.9 \%$ and the power of the fan is increased by $12.6 \sim 17.5 \%$ due to the installation of the air filter. Moreover, the installation of the air filter increases the sensible heat efficiency of the HRV system. However, the sensible heat transfer capacities of the HRV system in the three modes are slightly decreased. In addition, the case study shows that the integrated system installed in the residential apartment in winter not only improves the IAQ but also saves energy consumption for the fresh air heating compared with AC; and the application potential of the integrated system in the cold zones is better than that of the other three climate zones in China.

In future, more detailed experiments will be conducted to investigate the combined influence of the air flow rate, structure and temperature differences on the heat transfer performances of the HRV system. And also the influences of the running condition of the air filter on the performances of the HRV system will be carried out in the next work.

\section{Acknowledgments}

The experimental work was completed in the Renewable Energy Research Group (RERG) of The Hong Kong Polytechnic University, and financial support was given by the National Science Foundation of China (Grant No. 51408182) and The Hong Kong Polytechnic University. 


\section{Appendix}

Appendix Fig.1. Changing curves of the four temperatures with time of the integrated system (Min mode).

Appendix Fig.2. Relation curves of $t_{i n 1} \sim\left(t_{i n 1}-t_{\text {out } 1}\right)$ and $t_{\text {out } 2} \sim\left(t_{i n 1}-t_{\text {out } 1}\right)$ of the integrated system (Min mode).

Appendix Fig.3. Changing curves of the four temperatures with time of the HRV system (Norm mode).

Appendix Fig.4. Relation curves of $t_{i n 1} \sim\left(t_{i n 1}-t_{o u t 1}\right)$ and $t_{o u t 2} \sim\left(t_{i n 1}-t_{o u t 1}\right)$ of the HRV system (Norm mode).

Appendix Fig.5. Changing curves of the four temperatures with time of the integrated system (Norm mode).

Appendix Fig.6. Relation curves of $t_{\text {in } 1} \sim\left(t_{\text {in } 1}-t_{\text {out } 1}\right)$ and $t_{\text {out } 2} \sim\left(t_{i n 1}-t_{\text {out } 1}\right)$ of the integrated system (Norm mode).

Appendix Fig.7. Changing curves of the four temperatures with time of the HRV system (Max mode).

Appendix Fig.8. Relation curves of $t_{i n 1} \sim\left(t_{i n 1}-t_{\text {out } 1}\right)$ and $t_{\text {out } 2} \sim\left(t_{i n 1}-t_{\text {out } 1}\right)$ of the HRV system (Max mode).

Appendix Fig.9. Changing curves of the four temperatures with time of the integrated system

(Max mode).

Appendix Fig.10. Relation curves of $t_{i n 1} \sim\left(t_{i n 1}-t_{o u t 1}\right)$ and $t_{\text {out } 2} \sim\left(t_{i n 1}-t_{o u t 1}\right)$ of the integrated system (Max mode).

\section{References}

[1] J. Dieckmanu, K.W. Roth, J. Brodrick, Air-to-air energy recovery heat exchangers, ASHRAE Journal, 45(8)200357-58.

[2] R.M. Lazzarin, A. Gasparella, Technical and economical analysis of heat recovery in building ventilation systems, Applied Thermal Engineering, 18 (1-2) (1998) 47-67.

[3] M. Fehrm, W. Reiners, M. Ungemach, Exhaust air heat recovery in buildings, International Journal of Refrigeration, 25 (4) (2002) 439-449.

[4] GB 50189-2005, Design standard for energy efficiency of public buildings, 2005(in Chinese). 
[5] L.Z. Zhang, J.L. Niu, Energy requirements for conditioning fresh air and the long-term savings with an embrane-based energy recovery ventilator in Hong Kong, Energy, 26 (2001) $119-135$.

[6] L.Z. Zhang, X.R Zhang, Q.Z. Miao, L.X. Pei, Selective permeation of moisture and VOCs through polymer membranes used in total heat exchangers for indoor air ventilation, Indoor Air, 22(4), 2012:321-330.

[7] Patel H., Ge G.M., Abdel-Salam A.H. Mohamed, Abdel-Salam A.H., Contaminant transfer in run-around membrane energy exchangers, Energy and Buildings, 70(2014):94-105.

[8] E. L. Hult, H. Willem, M. H. Sherman, Formaldehyde transfer in residential energy recovery ventilators. Building and Environment, 75(2014)92-97.

[9] K. Zhong, Y.M. Kang, Applicability of air-to-air heat recovery ventilators in China, Applied Thermal Engineering, 29(2009)830-840.

[10] J.J. Liu, W.S. Li, J. Liu, B. Wang, Efficiency of energy recovery ventilator with various weathers and its energy saving performance in a residential apartment, Energy and Buildings, 42 (2010) 43-49.

[11] J.L. Zhang, A. S. Fung, S. J, Analysis and feasibility study of residential integrated heat and energy recovery ventilator with built-in economizer using an excel spreadsheet program, Energy and Buildings, 75 (2014) 430-438.

[12] J.X. Gu, Z.P. Bai, W.F. Li, L.P. Wu, A.X. Liu, H.Y. Dong, Y.Y. Xie, Chemical composition of PM 2.5 during winter in Tianjin, China, Particuology, 9 (2011) 215-221.

[13] D.W. Dockery, P.H. Stone, Cardiovascular risks from fine particulate air pollution, The New England Journal of Medicine, 356 (2007) 511-513.

[14] G. Norris, S.N. YoungPong, J.Q. Koenig, T. V. Larson, L., Sheppard, J. W. Stout, An association between fine particles and asthma emergency department visits for children in Seattle, Environmental Health Perspectives, 107 (1999) 489-493.

[15] J.Z. Wang, Y.Q. Wang, H. Liu, Y.Q. Yang, X.Y. Zhang, Y. Li, Diagnostic identification of the impact of meteorological conditions on PM2.5 concentrations in Beijing, Atmospheric Environment, 81(2013):158-165.

[16] Y.H. Pui David, S.C. Chen, Z.L. Zuo, PM2.5 in China: Measurements, sources, visibility and health effects, and mitigation, Particuology, 13 (2014) 1-26.

[17] SEPAC (State Environmental Protection Administration of China). (2012), Chinese ambient air quality standards, GB 3095-2012, Beijing: Ministry of Environmental Protection of the People's Republic of China.

[18] M.P. Spilak, G.D. Karottki, B. Kolarik, M. Frederiksen, S. Loft, L. Gunnarsen, Evaluation of building characteristics in 27 dwellings in Denmark and the effect of using particle filtration units on PM2.5 concentrations, Building and Environment, 73(2014)55-63.

[19] M. Zaatari, A. Novoselac, J. Siegel, The relationship between filter pressure drop, indoor air quality, an d energy consumption in rooftop HVAC units, Building and Environment, 73(2014)151-161.

[20] T. Marsik, R. Johnson, Use of Simulink to evaluate the air-quality and energy performance of HRV-euipped residences in Fairbanks, Alaska, Energy and Buildings, 40(2008)1605-1613.

[21] EN779: EN2012, Particulate filters for general ventilation- determination of the filter performance.

[22] ASHRAE. ANSI/ASHRAE Standard 84-1991 Method of testing air-to-air heat exchangers. 
[23] J.L. Zhang, A. S. Fung, Experimental and numerical investigation of the thermal impact of defrost cycle of residential heat and energy recovery ventilators, Energy and Buildings, 97 (2015) 129-136.

[24] WHO (2006). Air quality guidelines: Global update 2005. Geneva: World health organization, Retrieved February 21, 2016 from <http://apps.who.int/iris/bitstream/10665/69477/1/WHO_SDE_PHE_OEH_06.02_eng.pdf >.

[25] GraphPad Software, Inc., GraphPad Curve Fitting Guide, Retrieved February 21, 2016 from $<$ http://www.graphpad.com/guides/prism/6/curve-fitting/>.

[26] National standard of the people republic of China, Design code for heating ventilation and air conditioning of civil buildings, GB 50736-2012, China Building Industry Press, 2012 (in Chinese) 


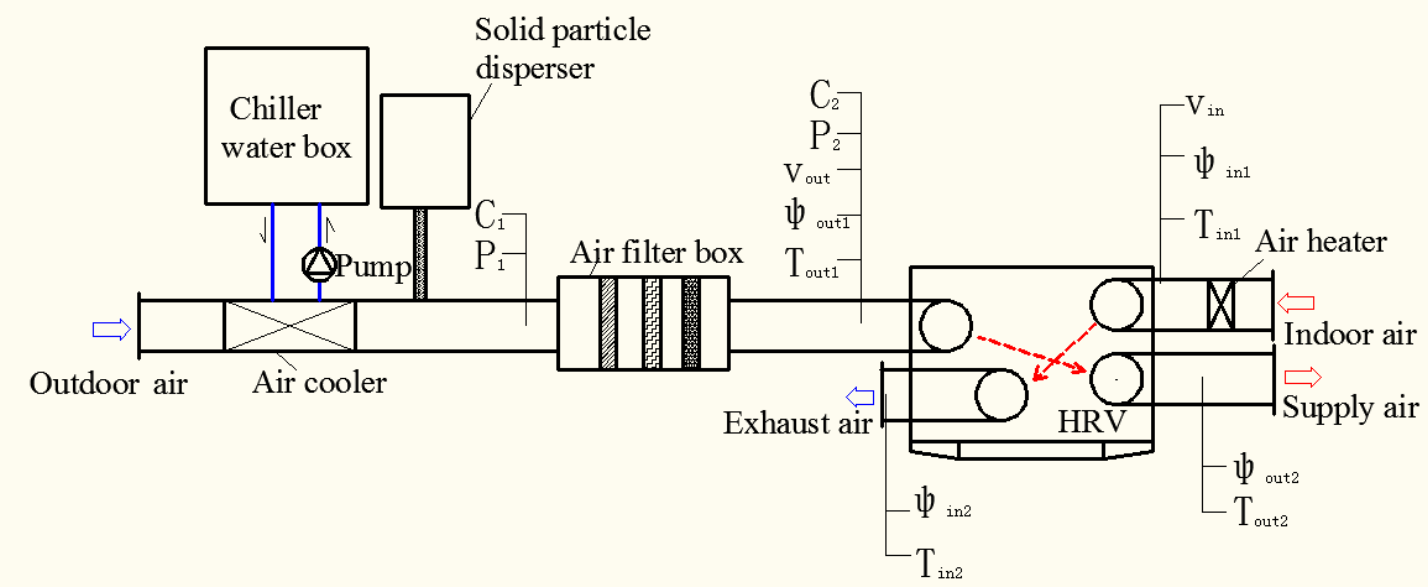

(a) Schematic diagram of the experimental facility.

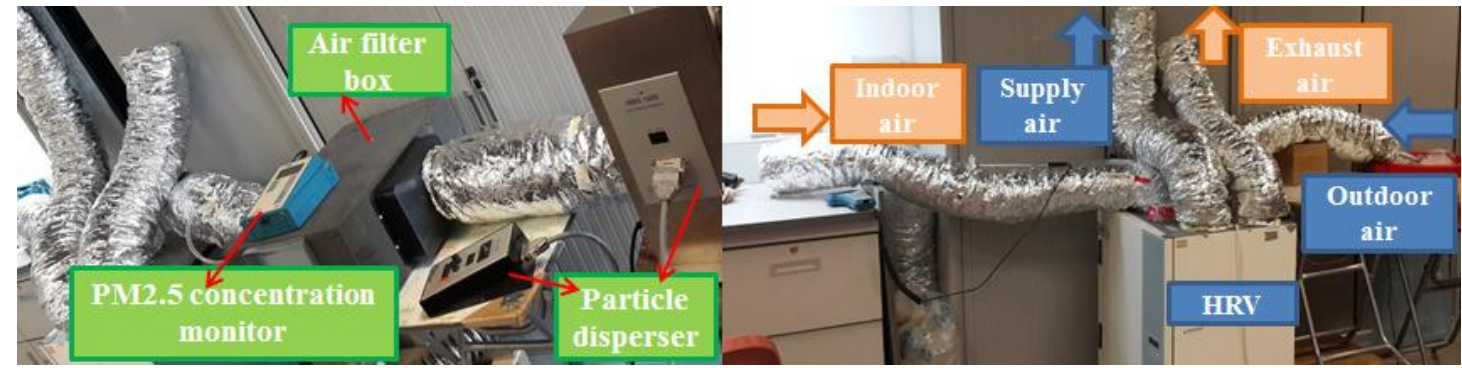

(b) Photos of the experimental setups.

Fig. 1. Experimental setup.

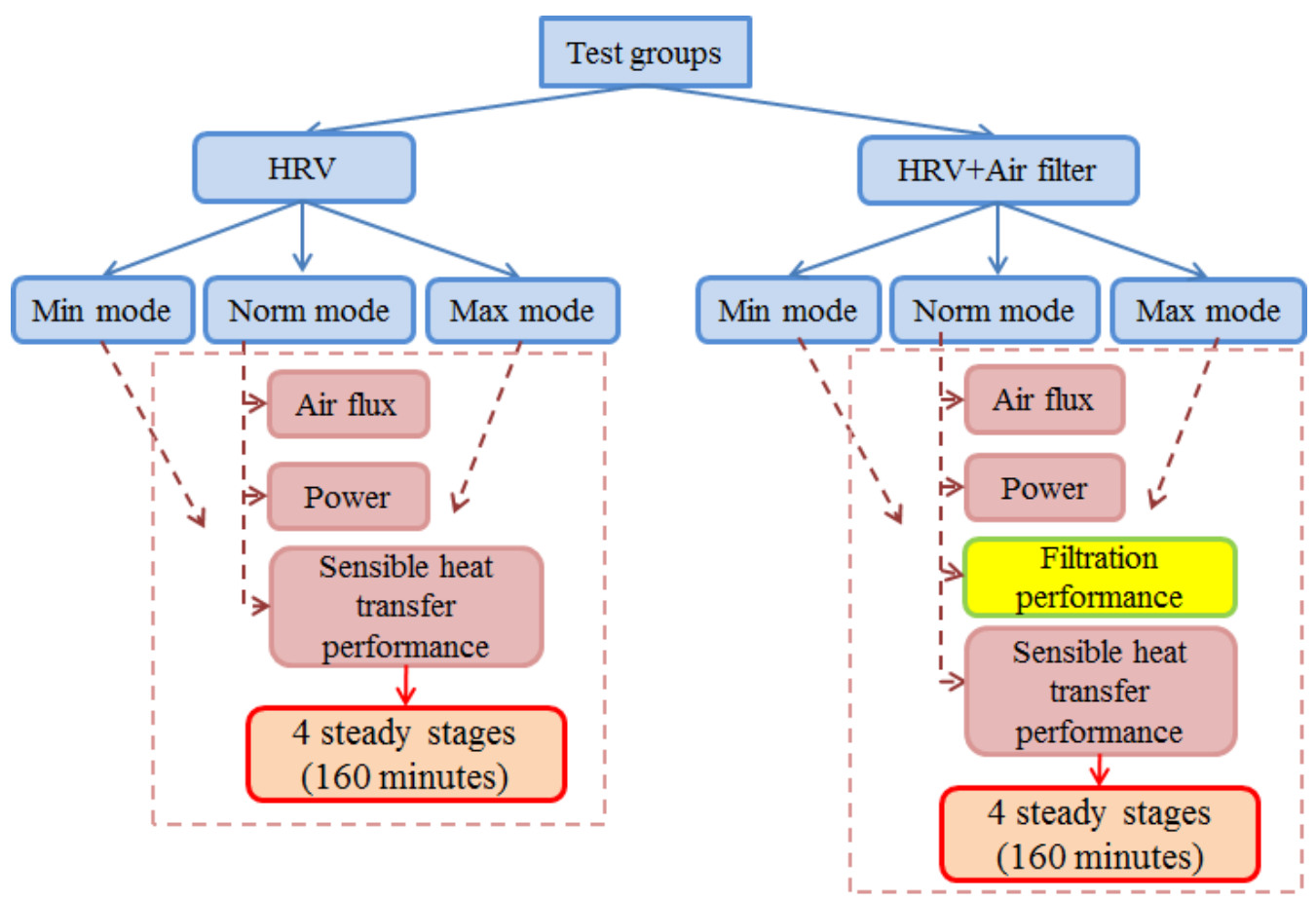

Fig. 2. The test processes. 

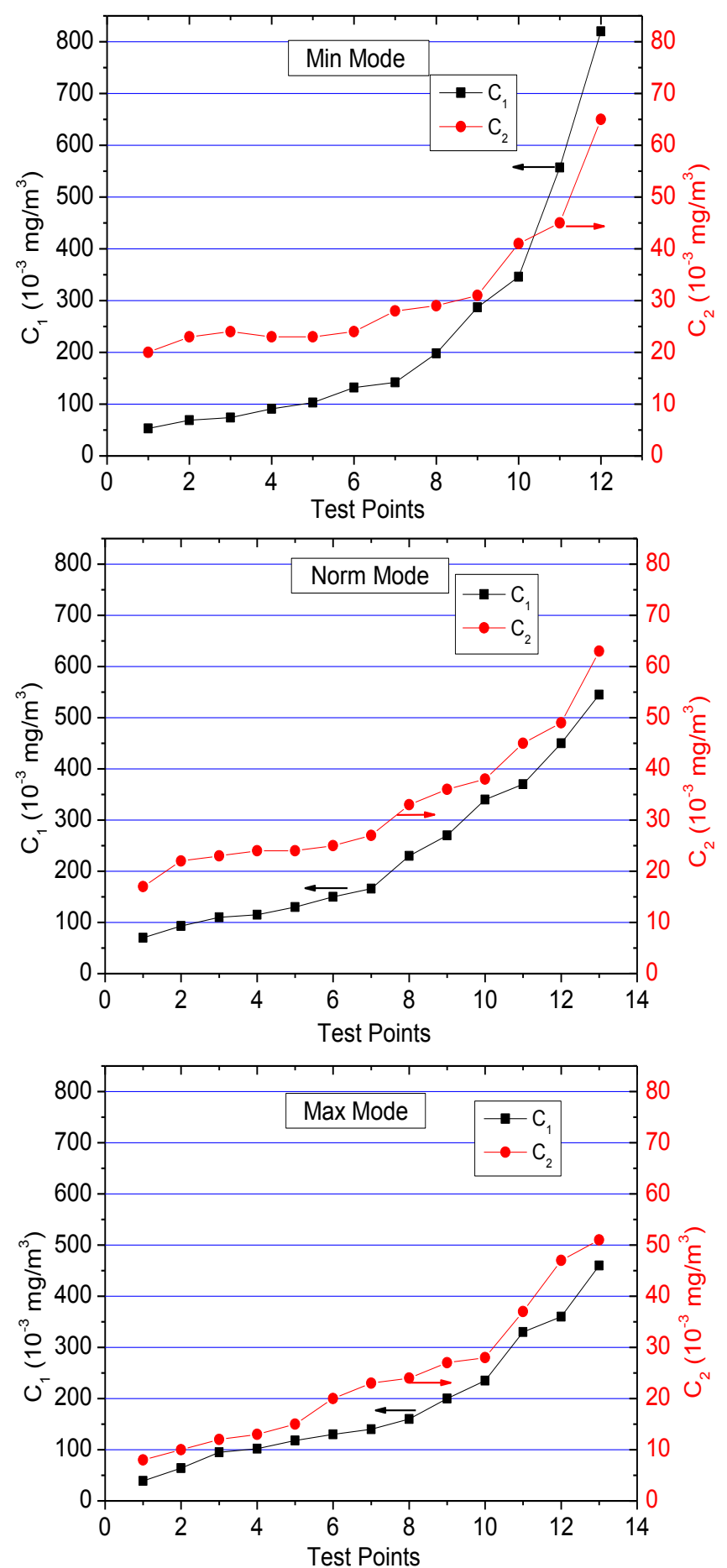

Fig. 3. Filtration effects of the air filter in the Min, Norm and Max modes. 
The 4th

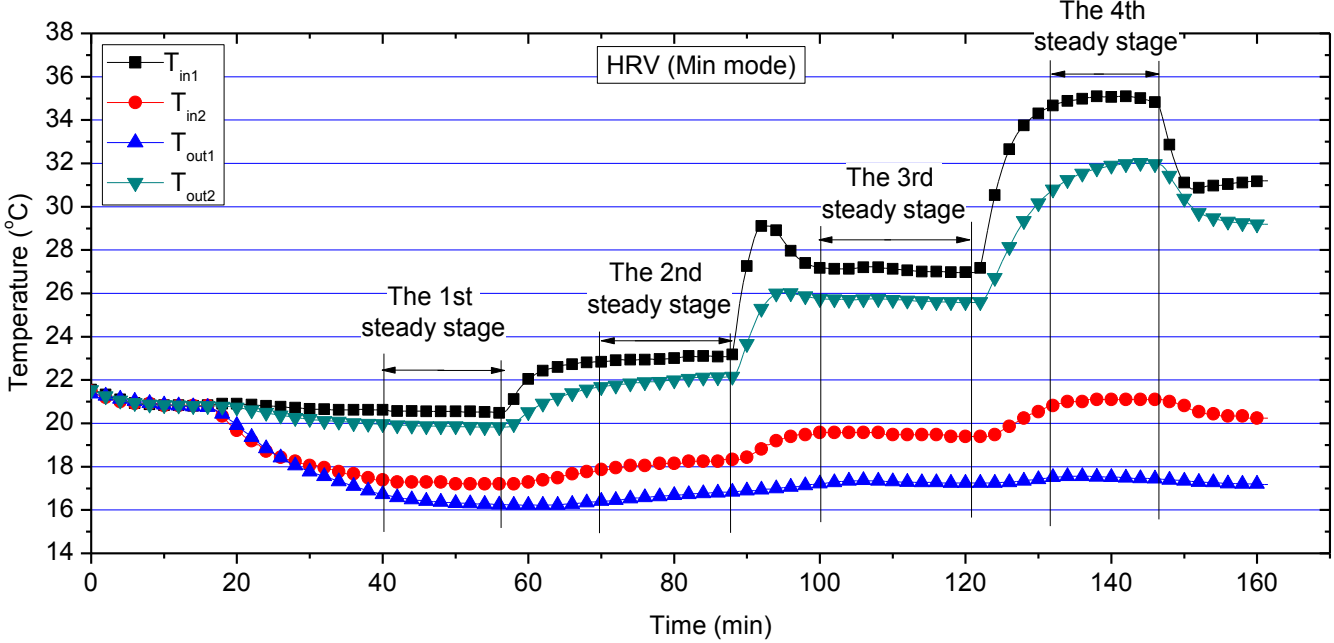

Fig. 4. Changing curves of the four temperatures with time of the HRV system (Min mode).

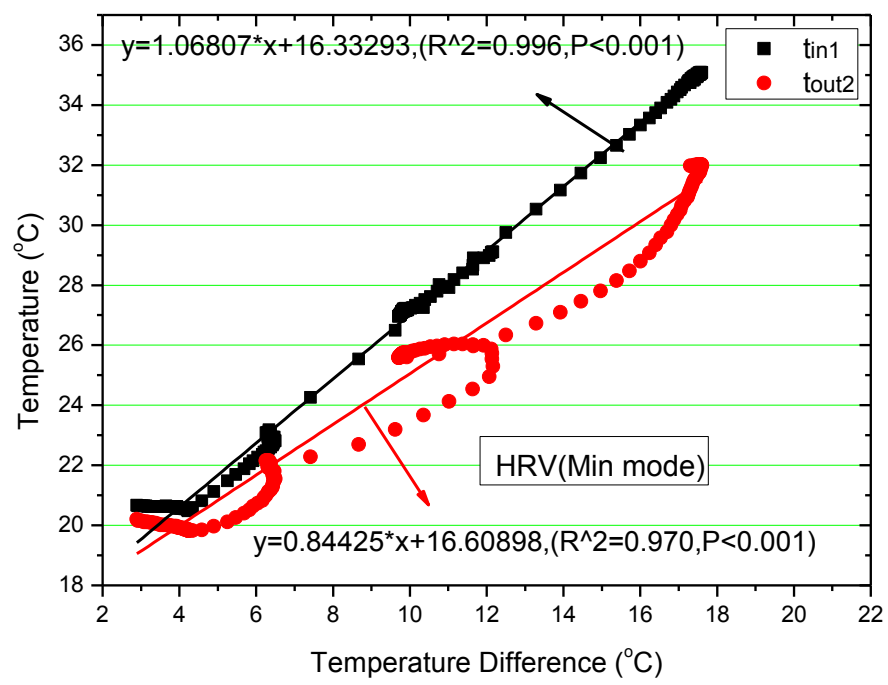

Fig.5 Relation curves of $t_{\text {in } 1} \sim\left(t_{\text {in } 1}-t_{\text {out } 1}\right)$ and $t_{\text {out } 2} \sim\left(t_{\text {in } 1}-t_{\text {out } 1}\right)$ of the HRV system (Min mode). 


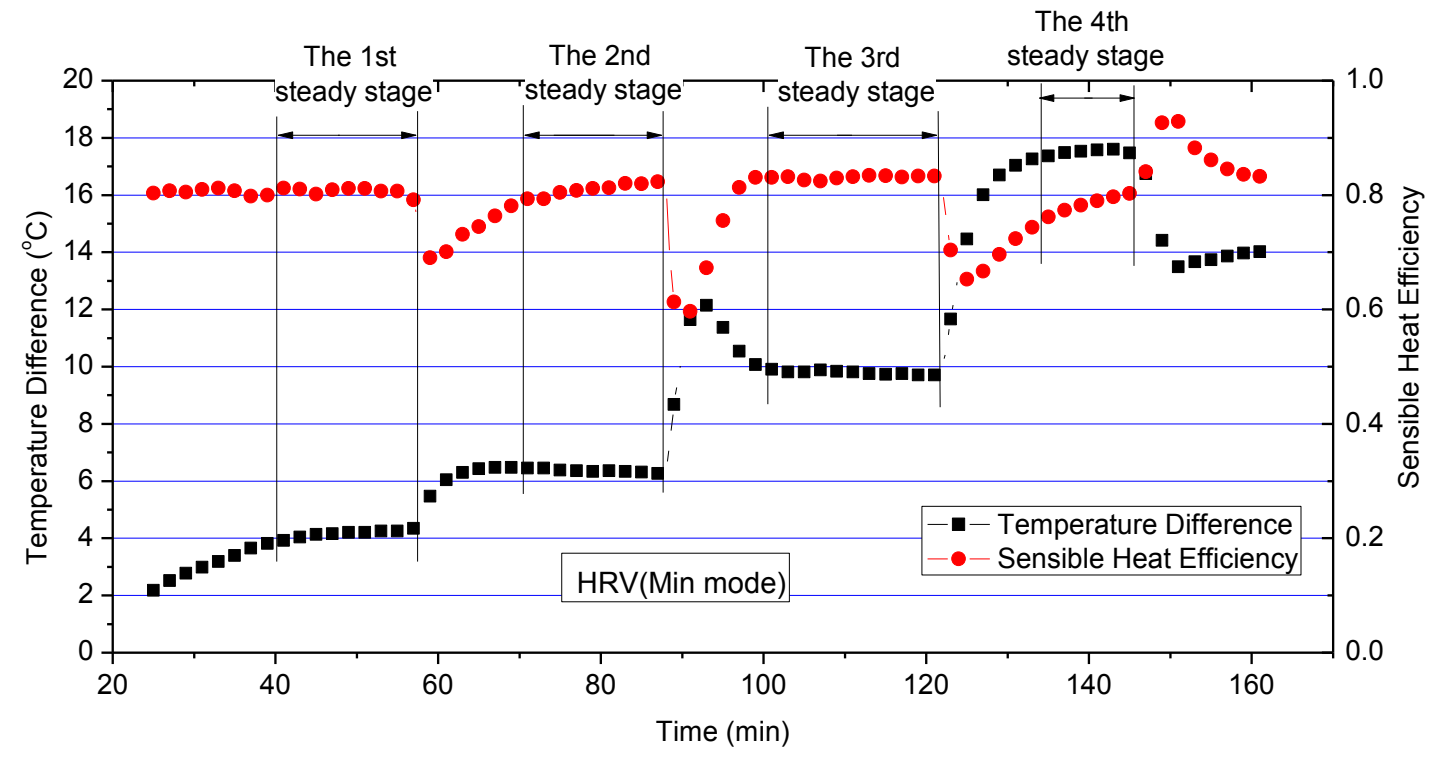

Fig. 6. Changing curves of the sensible heat efficiency and temperature difference with time of the HRV system (Min mode). 

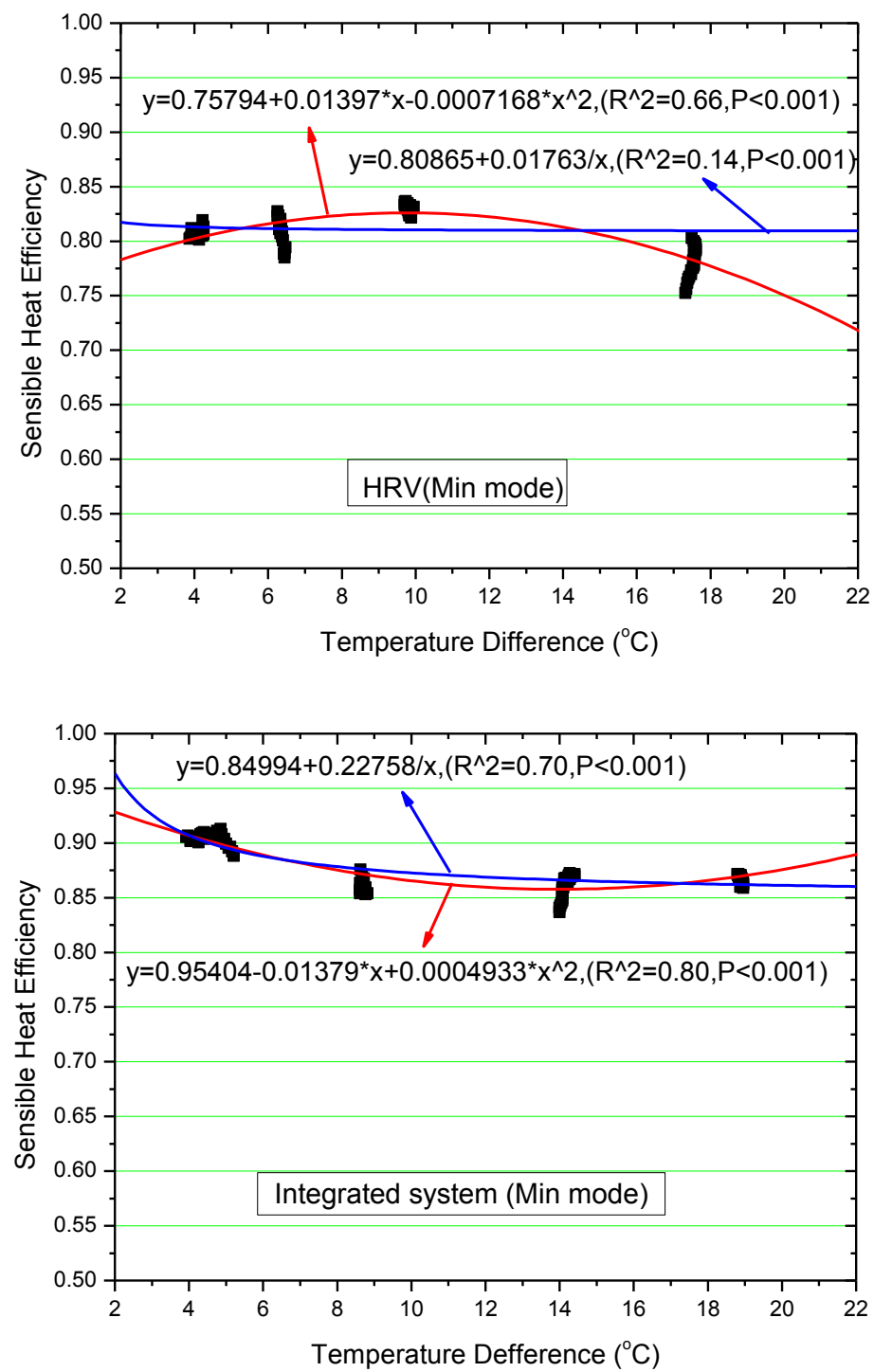

Fig. 7. Correlations for the sensible heat efficiency and temperature difference of the HRV and integrated system (Min mode). 

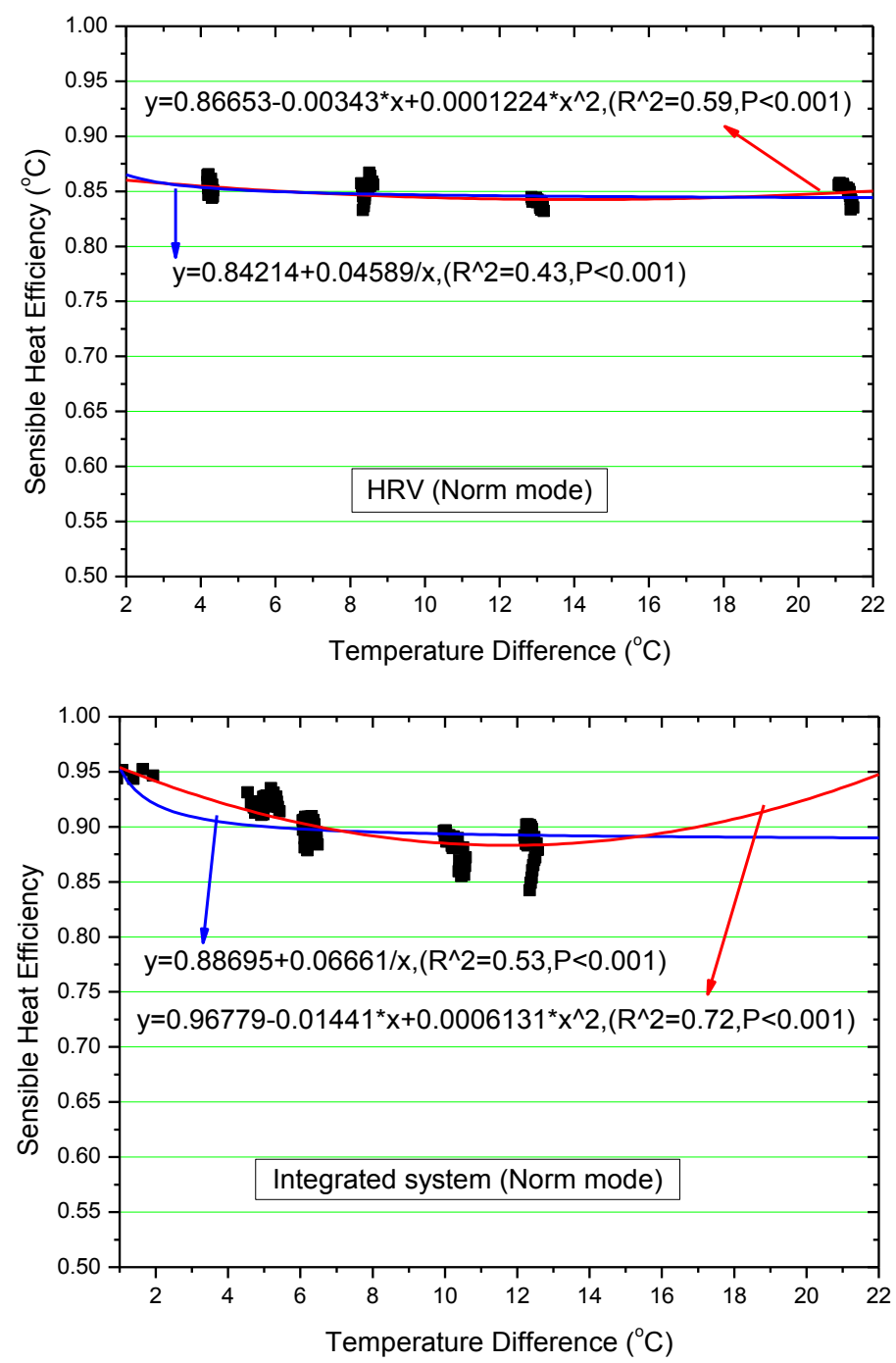

Fig. 8. Correlations for the sensible heat efficiency and temperature difference of the HRV and integrated system (Norm mode). 

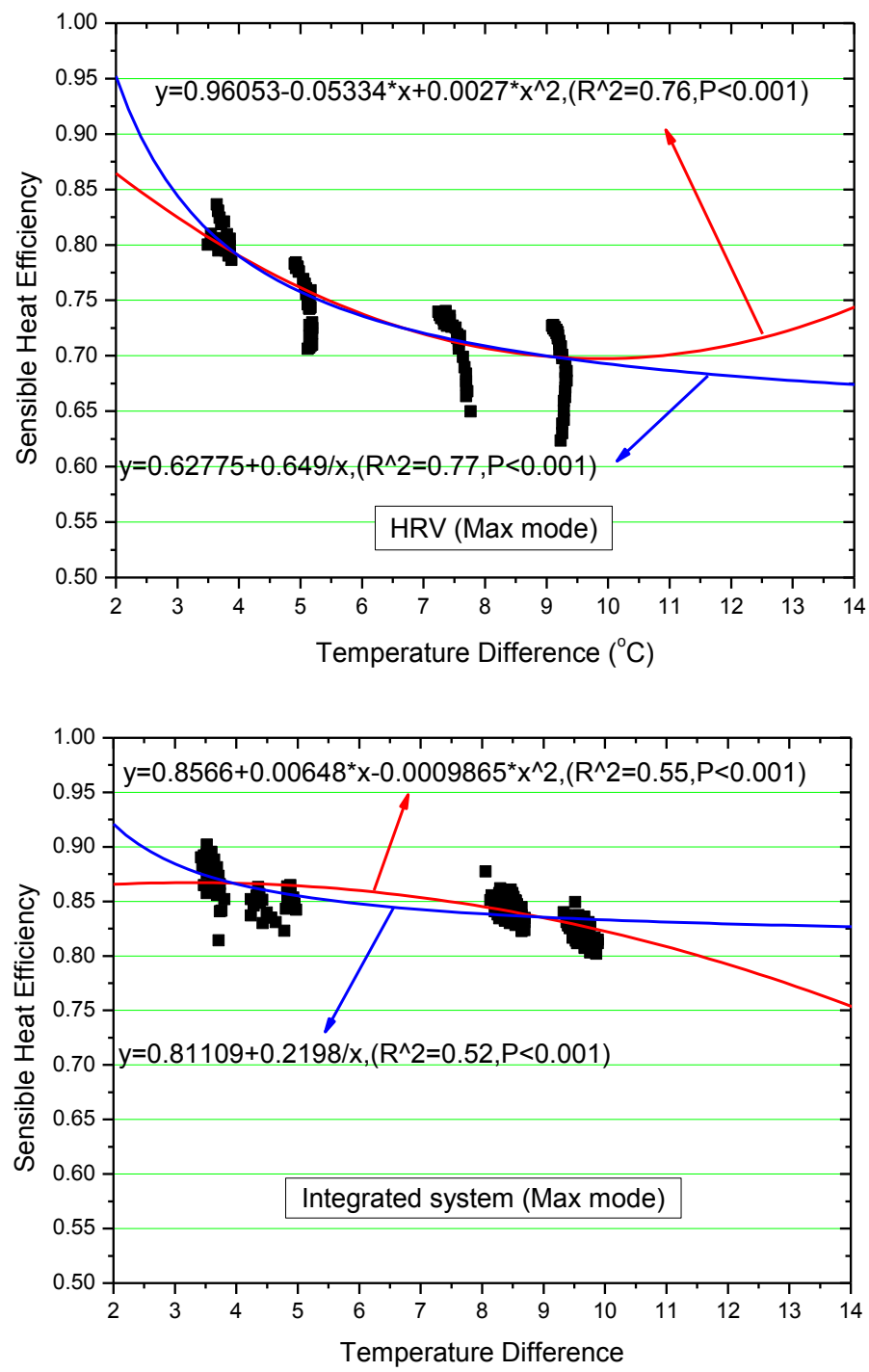

Fig. 9. Correlations for the sensible heat efficiency and temperature difference of the HRV and integrated system (Max mode). 


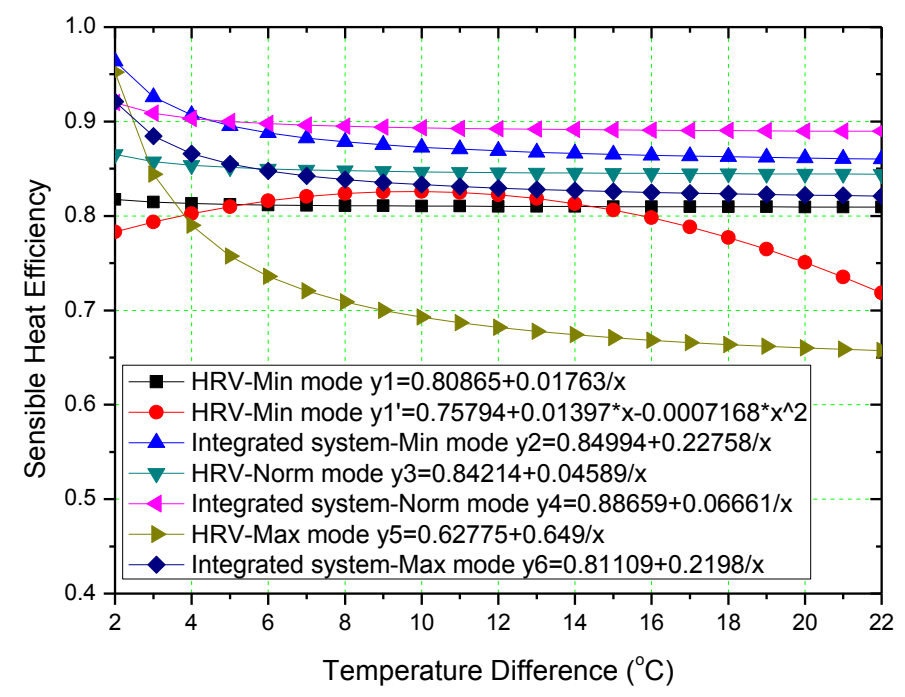

Fig.10. Changing curves of sensible heat efficiency with temperature difference between HRV and integrated systems in the three modes.

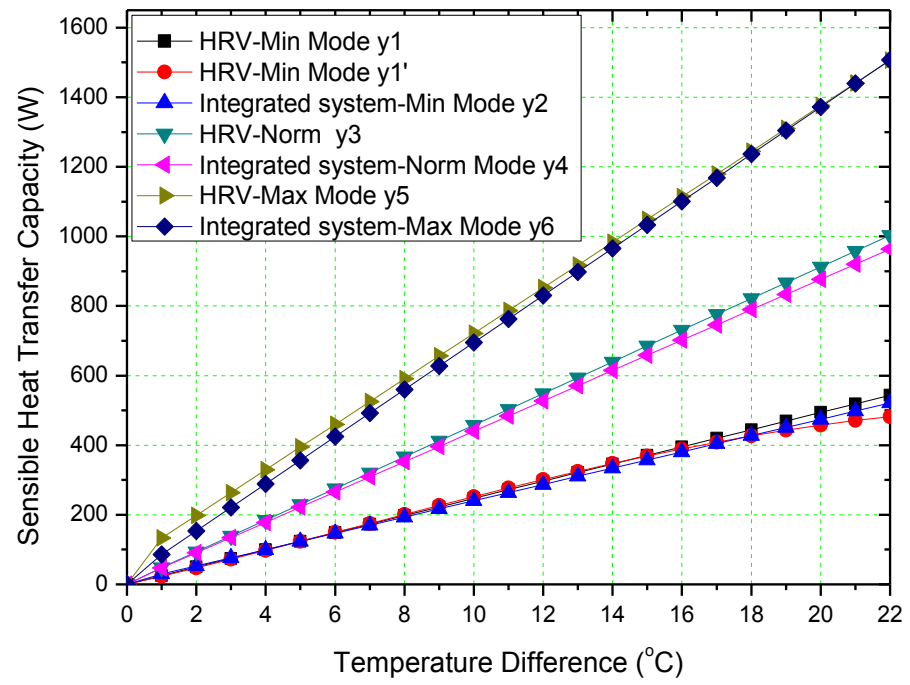

Fig.11. Changing curves of sensible heat transfer capacity with temperature difference between HRV and integrated systems in the three modes. (Notes: yi $\left(i=1,1^{\prime}, 2, \ldots \ldots, 6\right)$ indicates the sensible heat efficiency fitting formula as shown in Fig. 10 which is used to calculate the sensible heat transfer capacity). 


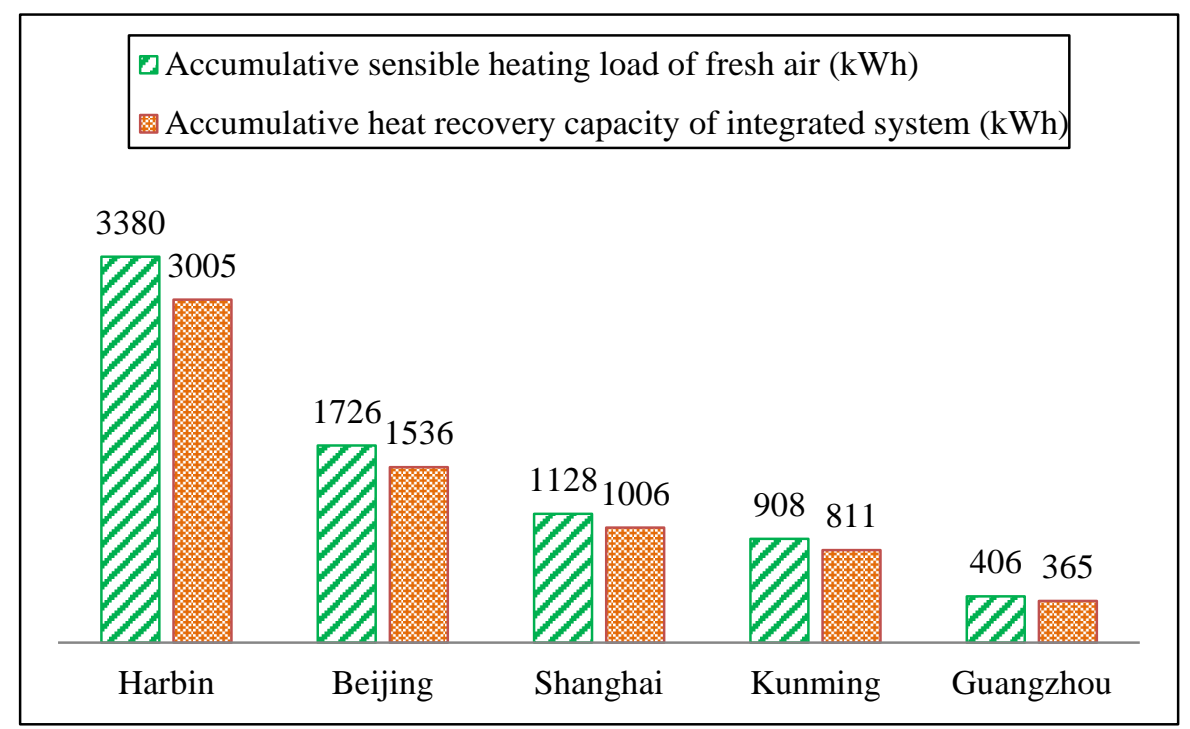

Fig. 12. The sensible heating loads of the accumulative fresh air and heat recovery capacities in the five cities.

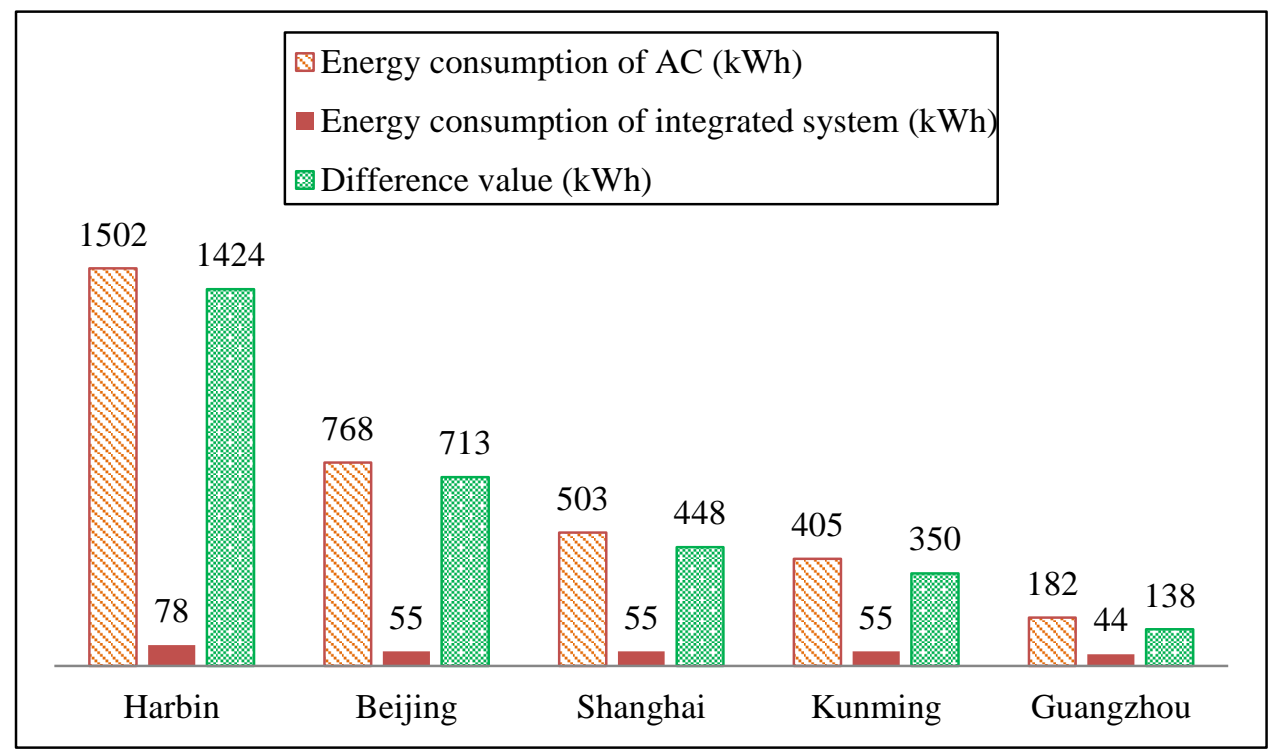

Fig. 13. The energy consumptions of AC and integrated system in the five cities. 


\section{Appendix}

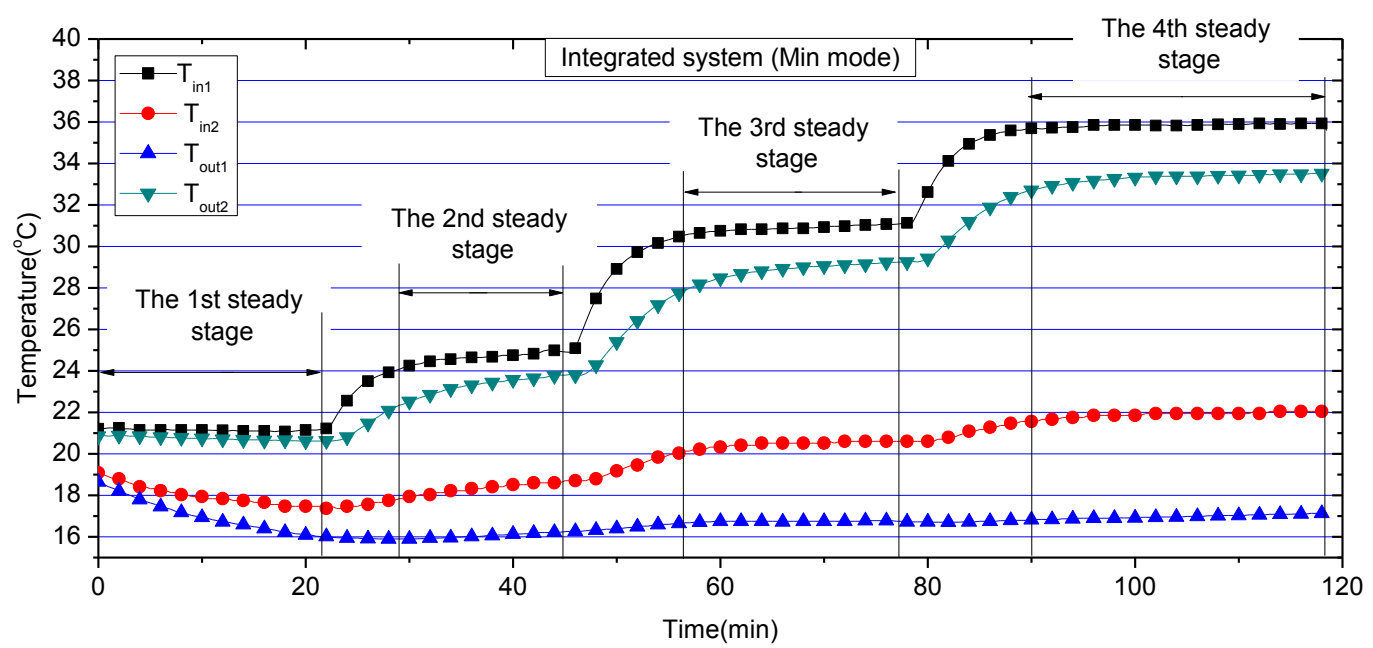

Appendix Fig.1. Changing curves of the four temperatures with time of the integrated system (Min mode).

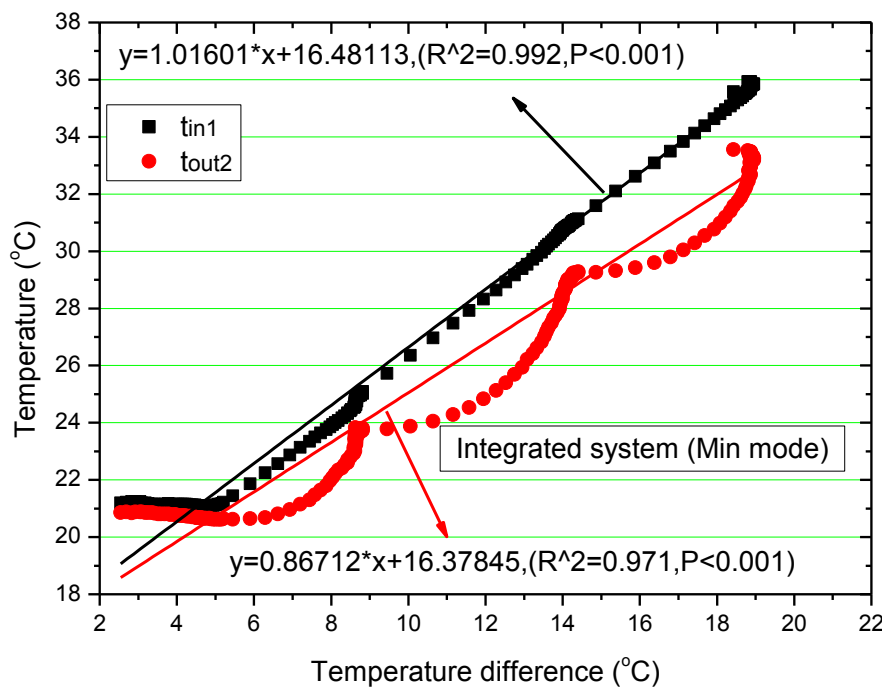

Appendix Fig.2. Relation curves of $t_{\text {in } 1} \sim\left(t_{\text {in } 1}-t_{\text {out } 1}\right)$ and $t_{\text {out } 2} \sim\left(t_{i n 1}-t_{\text {out } 1}\right)$ of the integrated system (Min mode). 


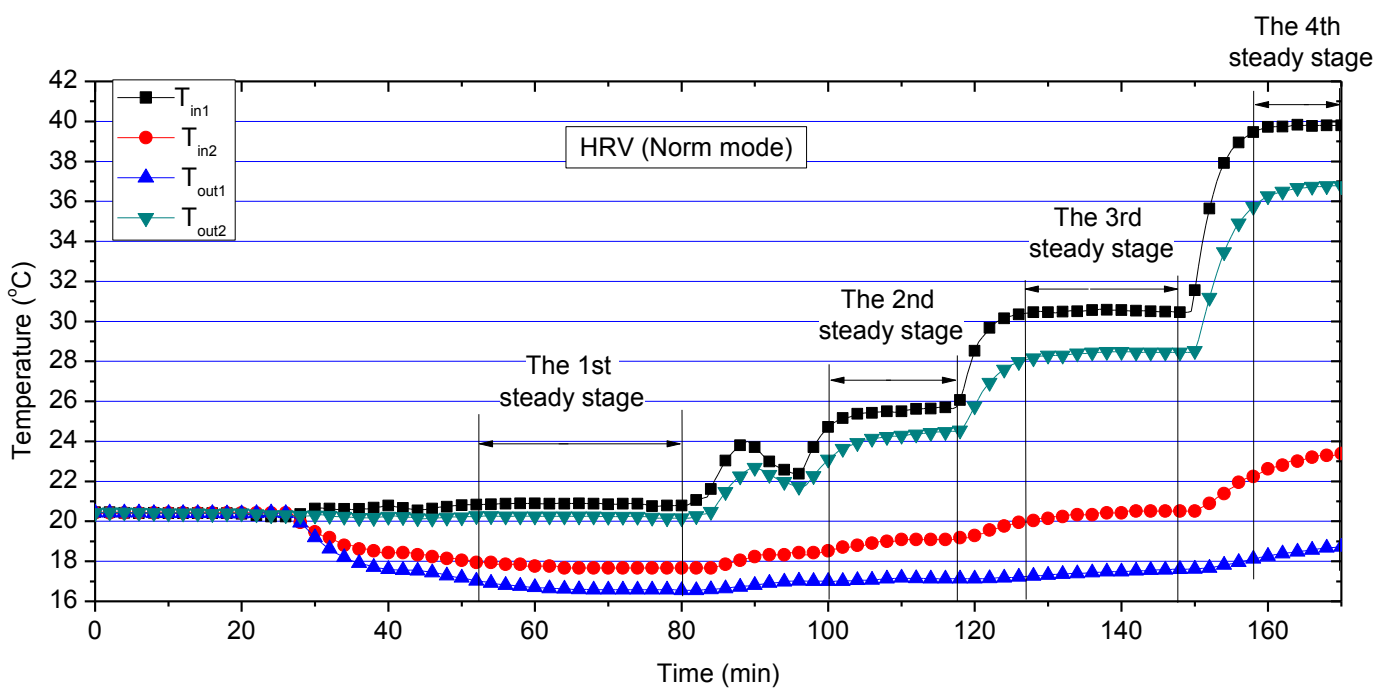

Appendix Fig.3. Changing curves of the four temperatures with time of the HRV system (Norm mode).

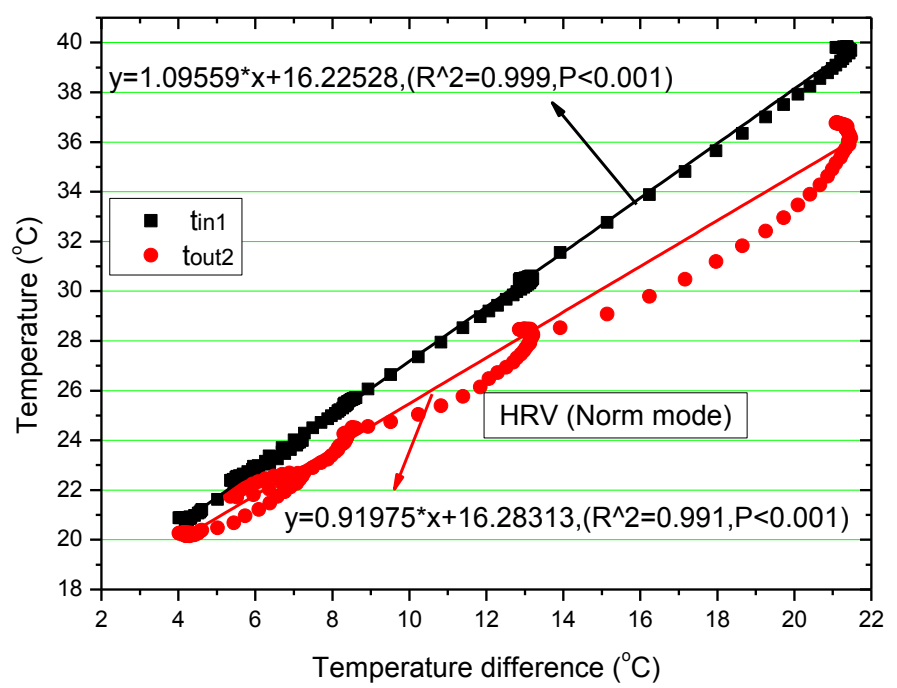

Appendix Fig.4. Relation curves of $t_{i n 1} \sim\left(t_{i n 1}-t_{\text {out } 1}\right)$ and $t_{\text {out } 2} \sim\left(t_{\text {in } 1}-t_{\text {out } 1}\right)$ of the HRV system (Norm mode). 


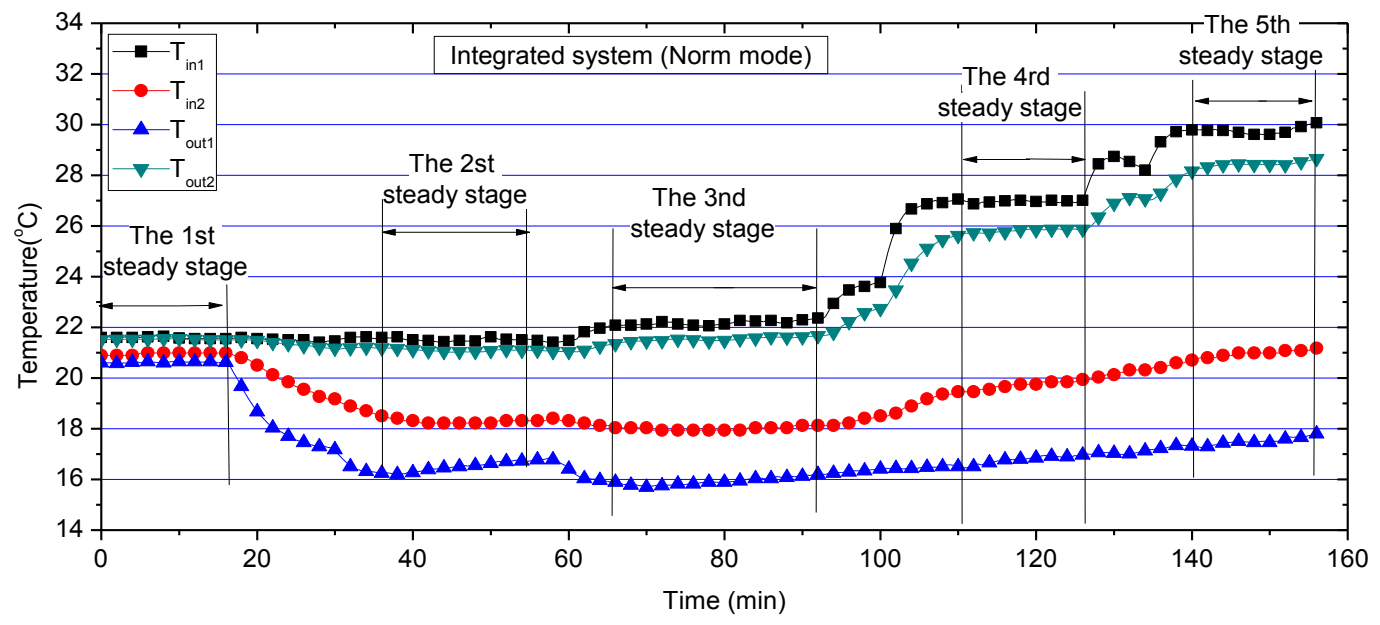

Appendix Fig.5. Changing curves of the four temperatures with time of the integrated system (Norm mode).

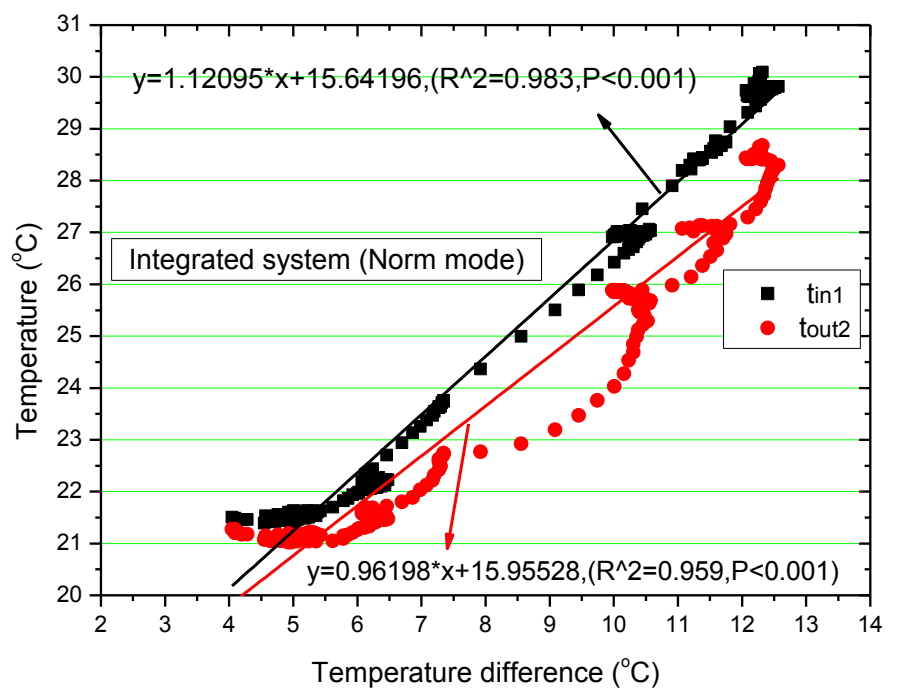

Appendix Fig.6. Relation curves of $t_{\text {in } 1} \sim\left(t_{i n 1}-t_{\text {out } 1}\right)$ and $t_{\text {out } 2} \sim\left(t_{i n 1}-t_{\text {out } 1}\right)$ of the integrated system (Norm mode). 


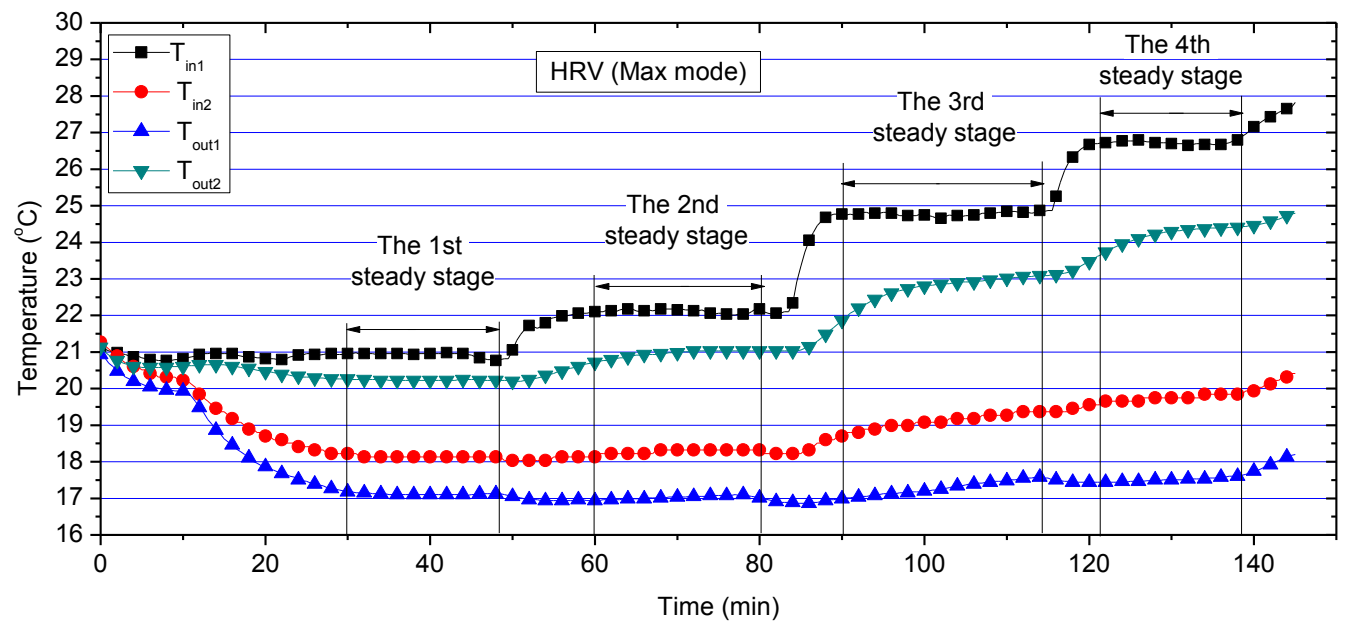

Appendix Fig.7. Changing curves of the four temperatures with time of the HRV system (Max mode).

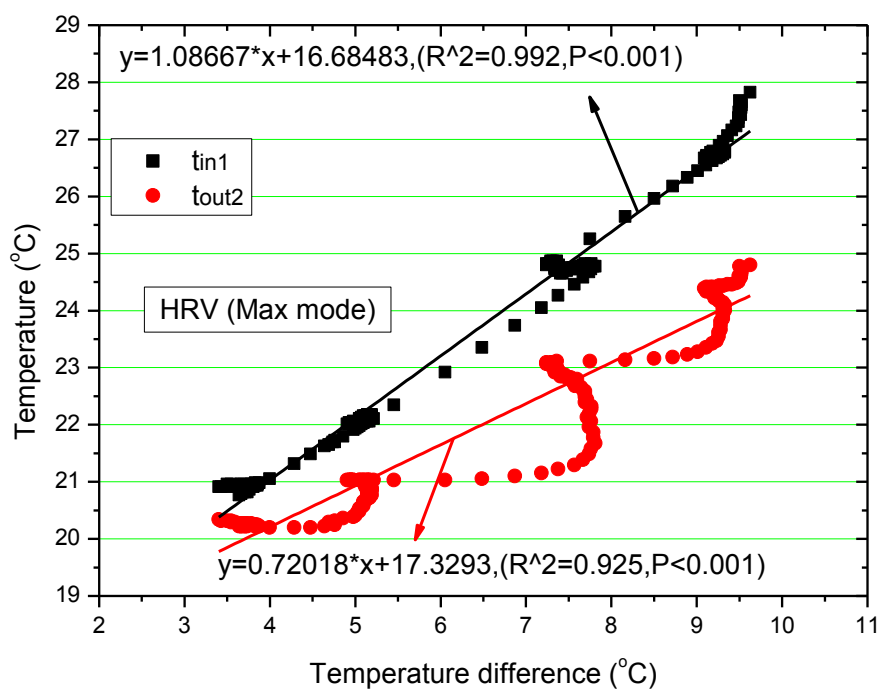

Appendix Fig.8. Relation curves of $t_{i n 1} \sim\left(t_{i n 1}-t_{o u t 1}\right)$ and $t_{o u t 2} \sim\left(t_{i n 1}-t_{o u t 1}\right)$ of the HRV system (Max mode). 


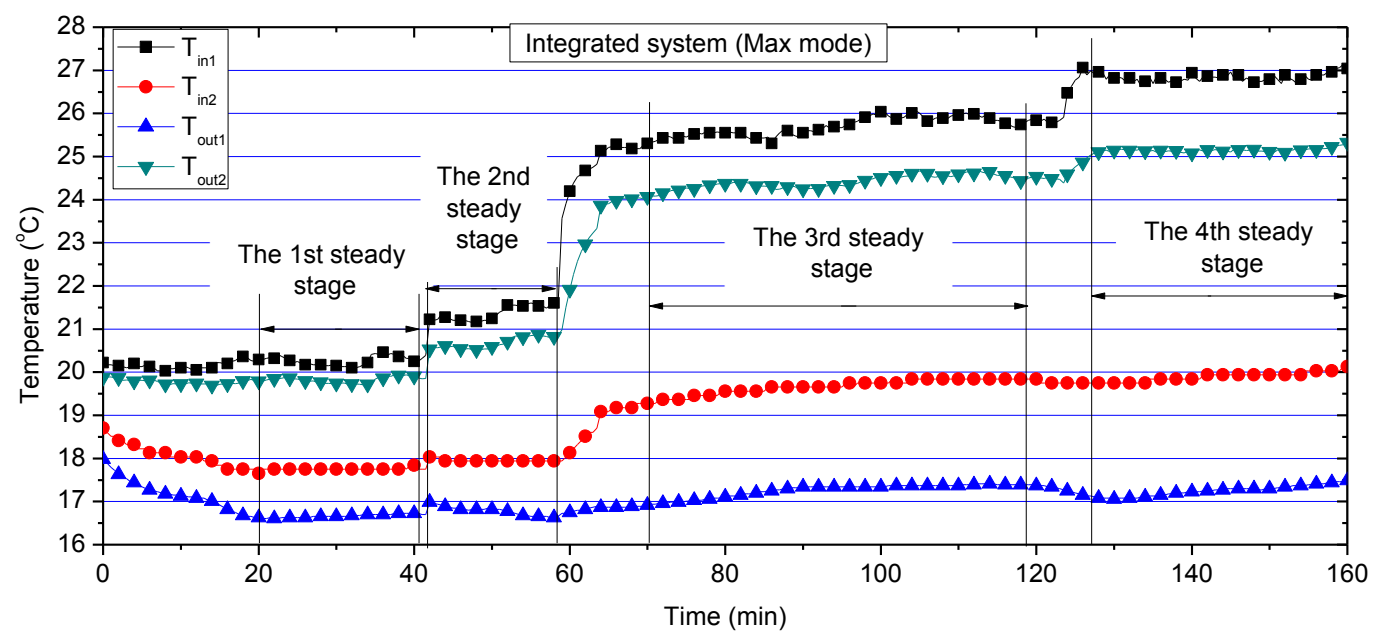

Appendix Fig.9. Changing curves of the four temperatures with time of the integrated system (Max mode).

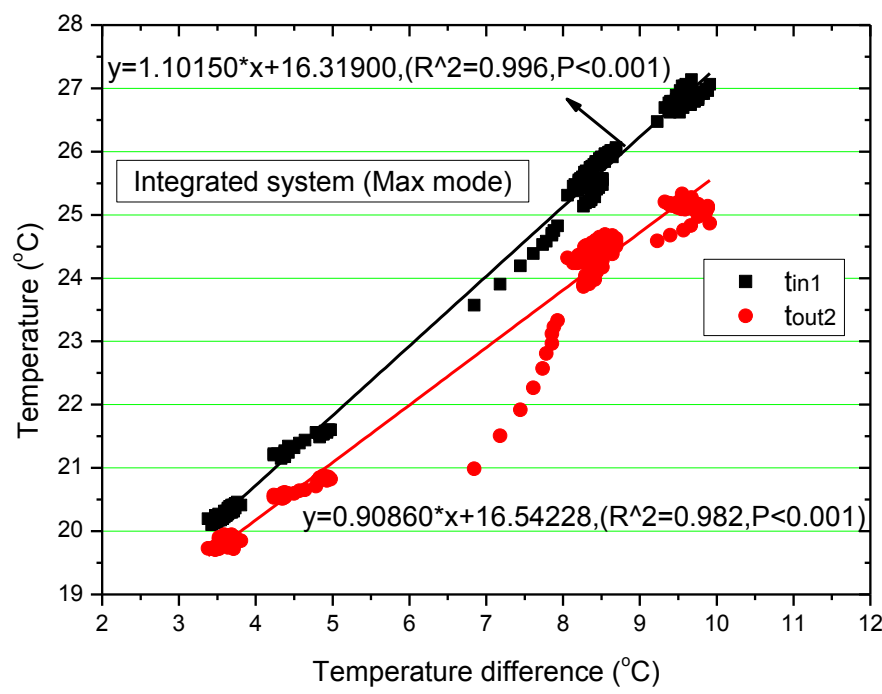

Appendix Fig.10. Relation curves of $t_{i n 1} \sim\left(t_{i n 1}-t_{\text {out } 1}\right)$ and $t_{\text {out } 2} \sim\left(t_{i n 1}-t_{\text {out } 1}\right)$ of the integrated system (Max mode). 
Table 1 Specifications of the Main Components of the Test Rig.

\begin{tabular}{|c|c|c|}
\hline Name & Type & Remarks \\
\hline HRV & $\begin{array}{l}\text { Counter-cross flow sensible plate heat } \\
\text { exchanger, VM1 type, manufactured } \\
\text { by Systemair AB in Sweden }\end{array}$ & 3 settings (Min, Norm and Max) \\
\hline Air filter & EU F7 & $116 \mathrm{~mm} \times 413 \mathrm{~mm} \times 50 \mathrm{~mm}$ \\
\hline $\begin{array}{l}\text { Solid particle } \\
\text { disperser }\end{array}$ & RGB 1000 (PALAS) & $\begin{array}{l}\text { Volume flow: } 0.5-5 \mathrm{~m}^{3} / \mathrm{h} \text {, Mass flow } \\
\text { Dependent on powder: } 40 \mathrm{mg} / \mathrm{h}-430 \mathrm{~g} / \mathrm{h}\end{array}$ \\
\hline Dust sample & Arizona test dust & Nominal 0-2 $\mu \mathrm{m}$ \\
\hline Pump & Submersible pump & $\begin{array}{l}\text { Rated input power: } 13.2 \mathrm{~W} \text {, Flow rate: } \\
450 \mathrm{~L} / \mathrm{h} \text {, Head: } 5 \mathrm{~m}\end{array}$ \\
\hline
\end{tabular}

Table 2 Specifications of instruments.

\begin{tabular}{lll}
\hline Parameters & Instruments & Accuracy \\
\hline $\mathrm{t}$ & Onset HOBO data loggers (Model: U12-11) & $\pm 0.35^{\circ} \mathrm{C}$ \\
$\varphi$ & Onset HOBO data loggers (Model: U12-11) & $\pm 2.5 \%$ \\
$\mathrm{v}$ & TSI VELOCICALC Plus Multi-Parameter Ventilation Meters & $\pm 0.015 \mathrm{~m} / \mathrm{s}$ \\
& (Model: 8386A) & \\
$\mathrm{P}$ & TSI DP-CALC air flow micro manometers (Model: 5825$)$ & $\pm 1 \mathrm{~Pa}$ \\
$\mathrm{C}$ & TSI DUSTTRAK Aerosol Particulate Monitors (Model: 5820) & $\pm 0.001 \mathrm{mg} / \mathrm{m}^{3}$ \\
Power & Electric power measuring meter (Model: TM9) & $\pm 0.1 \mathrm{~W}$ \\
\hline
\end{tabular}

Table 3 Basic performance parameters.

\begin{tabular}{lllll}
\hline Items & Objects & $\begin{array}{l}\text { Min Mode } \\
\text { (Uncertainty) }\end{array}$ & $\begin{array}{l}\text { Norm Mode } \\
\text { (Uncertainty) }\end{array}$ & $\begin{array}{l}\text { Max Mode } \\
\text { (Uncertainty) }\end{array}$ \\
\hline $\begin{array}{l}\text { Fresh air flux } \\
\left(\mathrm{m}^{3} / \mathrm{h}\right)\end{array}$ & HRV & $90.6( \pm 1.2 \%)$ & $160.5( \pm 1.0 \%)$ & $309.4( \pm 0.8 \%)$ \\
\hline \multirow{2}{*}{ Power $(\mathrm{W})$} & Integrated system & $81.8( \pm 1.2 \%)$ & $146.3( \pm 1.0 \%)$ & $247.8( \pm 0.9 \%)$ \\
\hline$\Delta \mathrm{P}(\mathrm{Pa})$ & HRV & $15.4( \pm 0.3 \%)$ & $26.9( \pm 0.2 \%)$ & $99.7( \pm 0.1 \%)$ \\
& Integrated system & $17.7( \pm 0.3 \%)$ & $30.5( \pm 0.2 \%)$ & $112.3( \pm 0.1 \%)$ \\
\hline
\end{tabular}

Table 4 WHO and China's standards for annual and 24-hour average PM2.5 concentration.

\begin{tabular}{llllll}
\hline \multirow{2}{*}{$\begin{array}{l}\text { WHO } \\
\text { Standard }\end{array}$} & Annual & $\begin{array}{l}\text { Standard } \\
\text { Value }\end{array}$ & $\begin{array}{l}\text { Interim } \\
\text { Target3 }\end{array}$ & $\begin{array}{l}\text { Interim } \\
\text { Target2 }\end{array}$ & $\begin{array}{l}\text { Interim } \\
\text { Target1 }\end{array}$ \\
\cline { 3 - 6 } & 10 & 15 & 25 & 35 \\
& 24-hr & 25 & 37.5 & 50 & 75 \\
\hline China & Annual & $15($ Level & I ) & 35 (Level & II ) \\
Standard & 24-hr & $35($ Level & I ) & 75 (Level & II) \\
\hline
\end{tabular}


Table 5 The sensible heat efficiencies based on the two regression methods.

\begin{tabular}{|c|c|c|c|c|c|c|c|c|c|c|c|c|}
\hline \multirow{3}{*}{$\begin{array}{c}\text { Temperature } \\
\text { difference } \\
\left({ }^{\circ} \mathrm{C}\right)\end{array}$} & \multicolumn{4}{|c|}{ Min mode } & \multicolumn{4}{|c|}{ Norm mode } & \multicolumn{4}{|c|}{ Max mode } \\
\hline & \multicolumn{2}{|c|}{ HRV system } & \multicolumn{2}{|c|}{ Integrated system } & \multicolumn{2}{|c|}{ HRV system } & \multicolumn{2}{|c|}{ Integrated system } & \multicolumn{2}{|c|}{ HRV system } & \multicolumn{2}{|c|}{ Integrated system } \\
\hline & User-defined & Polynomial & User-defined & Polynomial & User-defined & Polynomial & User-defined & Polynomial & User-defined & Polynomial & User-defined & Polynomial \\
\hline 2 & 0.8175 & 0.7830 & 0.9637 & 0.9284 & 0.8651 & 0.8602 & 0.9199 & 0.9414 & 0.9523 & 0.8647 & 0.9210 & 0.8656 \\
\hline 4 & 0.8131 & 0.8024 & 0.9068 & 0.9068 & 0.8536 & 0.8548 & 0.9032 & 0.9200 & 0.7900 & 0.7904 & 0.8660 & 0.8667 \\
\hline 6 & 0.8116 & 0.8160 & 0.8879 & 0.8891 & 0.8498 & 0.8504 & 0.8977 & 0.9034 & 0.7359 & 0.7377 & 0.8477 & 0.8600 \\
\hline 8 & 0.8109 & 0.8238 & 0.8784 & 0.8753 & 0.8479 & 0.8469 & 0.8949 & 0.8917 & 0.7089 & 0.7066 & 0.8386 & 0.8453 \\
\hline 10 & 0.8104 & 0.8260 & 0.8727 & 0.8655 & 0.8467 & 0.8445 & 0.8933 & 0.8850 & 0.6927 & 0.6971 & 0.8331 & 0.8228 \\
\hline 12 & 0.8101 & 0.8224 & 0.8689 & 0.8596 & 0.8460 & 0.8430 & 0.8921 & 0.8832 & 0.6818 & 0.7093 & 0.8294 & 0.7923 \\
\hline 14 & 0.8099 & 0.8130 & 0.8662 & 0.8577 & 0.8454 & 0.8425 & 0.8913 & 0.8862 & 0.6741 & 0.7430 & 0.8268 & 0.7540 \\
\hline 16 & 0.8098 & 0.7980 & 0.8642 & 0.8597 & 0.8450 & 0.8430 & 0.8908 & 0.8942 & 0.6683 & 0.7983 & 0.8248 & 0.7077 \\
\hline 18 & 0.8096 & 0.7772 & 0.8626 & 0.8656 & 0.8447 & 0.8444 & 0.8903 & 0.9071 & 0.6638 & 0.8752 & 0.8233 & 0.6536 \\
\hline 20 & 0.8095 & 0.7506 & 0.8613 & 0.8756 & 0.8444 & 0.8469 & 0.8899 & 0.9248 & 0.6602 & 0.9737 & 0.8221 & 0.5916 \\
\hline 22 & 0.8095 & 0.7183 & 0.8603 & 0.8894 & 0.8442 & 0.8503 & 0.8896 & 0.9475 & 0.6573 & 1.0939 & 0.8211 & 0.5217 \\
\hline 24 & 0.8094 & 0.6803 & 0.8594 & 0.9072 & 0.8441 & 0.8547 & 0.8894 & 0.9751 & 0.6548 & 1.2356 & 0.8202 & 0.4439 \\
\hline 26 & 0.8093 & 0.6366 & 0.8587 & 0.9290 & 0.8439 & 0.8601 & 0.8892 & 1.0076 & 0.6527 & 1.3989 & 0.8195 & 0.3582 \\
\hline 28 & 0.8093 & 0.5871 & 0.8581 & 0.9547 & 0.8438 & 0.8665 & 0.8890 & 1.0450 & 0.6509 & 1.5838 & 0.8189 & 0.2646 \\
\hline 30 & 0.8092 & 0.5319 & 0.8575 & 0.9843 & 0.8437 & 0.8738 & 0.8888 & 1.0873 & 0.6494 & 1.7903 & 0.8184 & 0.1632 \\
\hline
\end{tabular}

Table 6 Descriptions of the sample building.

\begin{tabular}{ll}
\hline Items & Description \\
\hline Area & $100 \mathrm{~m}^{2}$ \\
Floor to height & $2.9 \mathrm{~m}$ \\
Occupancy & 4 person \\
Space design temperature & $21{ }^{\circ} \mathrm{C}$ \\
Air changes per hour & $0.5(\mathrm{~GB} 50376-2012)$ \\
\hline
\end{tabular}

Table 7 Operation schedules of the integrated system.

\begin{tabular}{lll}
\hline City & Operation schedule & Note \\
\hline Harbin & Oct.-Apr. & \\
Beijing & Nov.-Mar. & Running for \\
Shanghai & Nov.-Mar. & 12 hours per \\
Kunming & Nov.-Mar. & day \\
Guangzhou & Dec.-Mar. & \\
\hline
\end{tabular}

